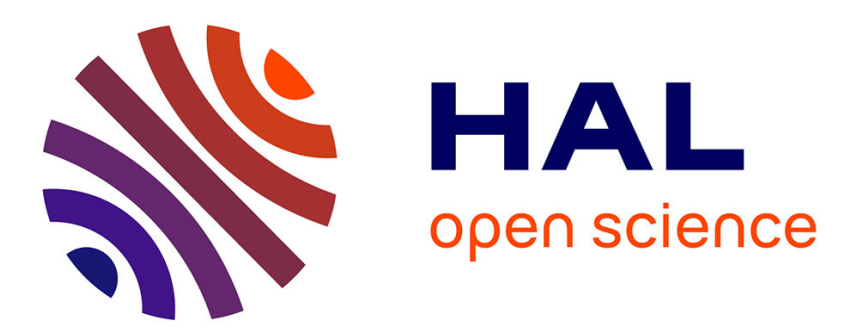

\title{
Mechanotransduction's Impact on Animal Development, Evolution, and Tumorigenesis
}

\author{
Maria-Elena Fernandez-Sanchez, Thibaut Brunet, Jens-Christian M Röper, \\ Emmanuel Farge
}

\section{- To cite this version:}

Maria-Elena Fernandez-Sanchez, Thibaut Brunet, Jens-Christian M Röper, Emmanuel Farge. Mechanotransduction's Impact on Animal Development, Evolution, and Tumorigenesis. Annual Review of Cell and Developmental Biology, 2015, 31 (1), pp.373-397. 10.1146/annurev-cellbio-102314112441 . inserm-02441081

\section{HAL Id: inserm-02441081 https://www.hal.inserm.fr/inserm-02441081}

Submitted on 15 Jan 2020

HAL is a multi-disciplinary open access archive for the deposit and dissemination of scientific research documents, whether they are published or not. The documents may come from teaching and research institutions in France or abroad, or from public or private research centers.
L'archive ouverte pluridisciplinaire HAL, est destinée au dépôt et à la diffusion de documents scientifiques de niveau recherche, publiés ou non, émanant des établissements d'enseignement et de recherche français ou étrangers, des laboratoires publics ou privés. 
Annu. Rev. Cell Dev. Biol. 2015. 31:373-97

First published online as a Review in Advance on September 24, 2015

The Annual Review of Cell and Developmental Biology is online at cellbio.annualreviews.org

This article's doi:

10.1146/annurev-cellbio-102314-112441

Copyright (c) 2015 by Annual Reviews. All rights reserved

\section{Maria-Elena Fernandez-Sanchez, ${ }^{1}$ Thibaut Brunet, ${ }^{1,2}$ Jens-Christian Röper, ${ }^{1}$ and Emmanuel Farge ${ }^{1}$}

${ }^{1}$ Mechanics and Genetics of Embryonic and Tumor Development Team, CNRS UMR 168 Physicochimie Curie, Institut Curie Centre de Recherche, PSL Research University; Fondation Pierre-Gilles de Gennes; and INSERM, F-75005 Paris, France; email: efarge@curie.fr

${ }^{2}$ Evolution of the Nervous System in Bilateria Group, European Molecular Biology Laboratory, D-69117 Heidelberg, Germany

\section{Keywords}

morphogenesis, mechanical pressure, endocytosis, conformation modulation, mechanical stiffness, mesoderm emergence, evo-devo

\section{Abstract}

Mechanotransduction translates mechanical signals into biochemical signals. It is based on the soft-matter properties of biomolecules or membranes that deform in response to mechanical loads to trigger activation of biochemical reactions. The study of mechanotransductive processes in cell-structure organization has been initiated in vitro in many biological contexts, such as examining cells' response to substrate rigidity increases associated with tumor fibrosis and to blood flow pressure. In vivo, the study of mechanotransduction in regulating physiological processes has focused primarily on the context of embryogenesis, with an increasing number of examples demonstrating its importance for both differentiation and morphogenesis. The conservation across species of mechanical induction in early embryonic patterning now suggests that major animal transitions, such as mesoderm emergence, may have been based on mechanotransduction pathways. In adult animal tissues, permanent stiffness and tissue growth pressure contribute to tumorigenesis and appear to reactivate such conserved embryonic mechanosensitive pathways. 


\section{Contents}

GENETIC REGULATION OF MORPHOGENESIS: TISSUE GROWTH

AND MYO-II ANISOTROPY ................................ 374

Proliferation and Growth ........................................ 374

Apicobasal Myo-II Anisotropy..................................... 375

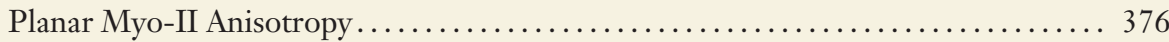

Actomyosin Cables and Boundary Stabilization...................... 376

MECHANOTRANSDUCTIVE, MORPHOGENETIC REGULATION

OF MYO-II ANISOTROPY AND TISSUE GROWTH ................... 376

Mechanotransductive Cues in the Establishment of Myo-II Apicobasal Polarity . . . 376

Mechanotransductive Maintenance of Myo-II Junctional Planar Polarity . . . . . . . . 378

Mechanotransductive Feedback in Tissue Growth Regulation................. 378

MECHANOTRANSDUCTIVE, MORPHOGENETIC REGULATION

OF EMBRYONIC TISSUE DIFFERENTIATION . . . . . . . . . . . . . . . . . . . . . 379

Mechanotransduction in the Differentiation of Cultured Cells ............... 379

Mechanical Induction of Embryonic Patterning and Differentiation In Vivo ...... 380

MECHANOTRANSDUCTION IN THE COURSE OF EVOLUTION ......... 382

Mechanotransduction in Key Evolutionary Transitions in Animals ............. 382

The Mechanotransductive Pathways and Their Phylogeny ................ 384

HYPERPROLIFERATION AND INCREASED STIFFNESS IN TUMOR

DEVELOPMENT MECHANICALLY REACTIVATES EMBRYONIC

$\beta$-CATENIN-DEPENDENT DEVELOPMENTAL PATHWAYS . . . . . . . 387

CONCLUSION .............................................. 390

\section{GENETIC REGULATION OF MORPHOGENESIS: TISSUE GROWTH AND MYO-II ANISOTROPY}

Much of our understanding of genetically regulated biomechanical morphogenesis, as well as of mechanosensitive pathways in development, arises from studies in Drosophila; thus, these are used as a focus of the review, and related to the connected cases having been found in other species.

\section{Proliferation and Growth}

Embryonic patterning is regulated by developmental genes, including the Hox genes, which determine anteroposterior patterning (Di-Poi et al. 2010), as well as dorsoventral patterning genes (St. Johnston \& Nusslein-Volhard 1992) (Figure 1a). By contrast, the mechanical contribution to tissue morphogenesis has traditionally been associated with tissue growth induced by cell proliferation (Thompson 1917) (Figure 1 b). For instance, the proliferation of epithelial cells physically connected to a sheet of connective tissue has been proposed to generate the buckling driving force that initiates villous morphogenesis of intestinal and colonic tissues (Edwards \& Chapman 2007, Hannezo et al. 2011, Shraiman 2005) (Figure 1c). Proliferation is genetically stimulated by cell-cycle regulators such as cyclin B, $c$-jun, c-myc, and $n$-myc (Nusse 2014). During embryogenesis, mitotic domains are genetically patterned (Foe 1989). Chemical signals that form gradients, called 
a

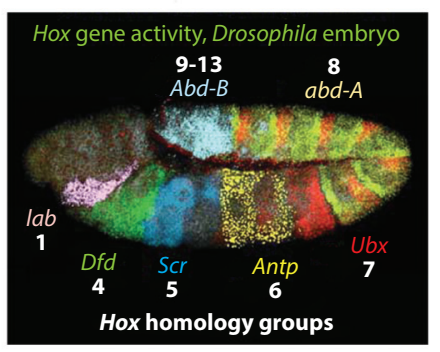

b

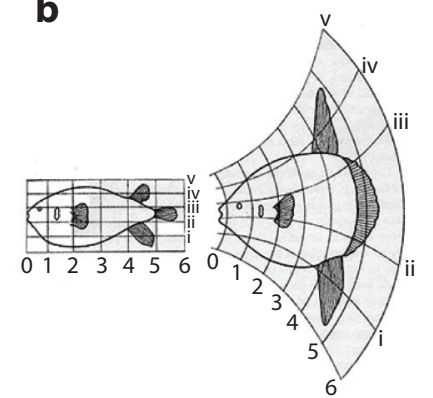

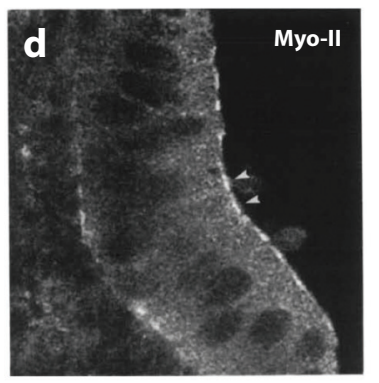

.

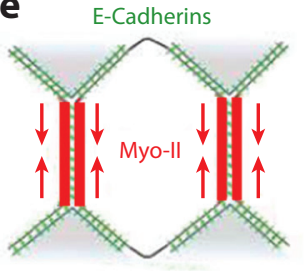

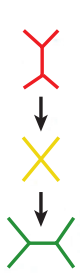

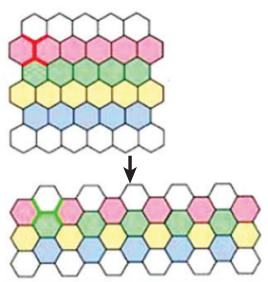

Figure 1

(a) Anteroposterior patterning of Drosophila embryos by Hox genes (http://pixgood.com/hox-genes-drosophila.html).

(b) Modulation of animal shape through changes in tissue growth (Thompson 1917). (c) Tissue bending as the result of 2D epithelial growth (adapted from Shraiman 2005). (d) Tissue bending as the result of tissue-patterned, intracellular, anisotropic, apical accumulation of nonmuscle myosin-II (Myo-II) in the posterior endoderm of the Drosophila embryo (adapted with permission from Young et al. 1991). (e) The planar polarity of Myo-II, the driving force behind tissue convergence-extension (adapted with permission from Bertet et al. 2004). E-Cadherins ensures cell-cell adhesion.

morphogens, function as instructive signals for patterning but also as growth factors within tissues. Examples include the secreted ligands Dpp and Wnt (Wartlick et al. 2011).

\section{Apicobasal Myo-II Anisotropy}

Before being influenced by differential cell proliferation, tissue morphogenesis is driven by temporal and spatial regulation of the intracellular molecular motor nonmuscle myosin-II (Myo-II), which acts downstream of developmental patterning genes. The requirement for such anisotropy was first observed during posterior endoderm invagination in gastrulating Drosophila embryos (Young et al. 1991) (Figure 1d ). Here, patterned apical submembrane cortical accumulation of Myo-II was demonstrated to generate actomyosin constriction, leading to a decrease in the apical surface area $($ Figure $1 \boldsymbol{d})$. This decrease, together with a passive increase in the noncontractile basal surface area, which results from maintaining constant internal volume, generates the curvature leading to invagination. Mesoderm invagination in Drosophila embryos follows the same principle, with medioapical stabilization of Myo-II under the control of the dorsoventral patterning transcription factors Snail and Twist (Dawes-Hoang et al. 2005, Martin 2009). Interestingly, medioapical accumulation of Rok kinase, which triggers apical accumulation of Myo-II, requires these two transcription factors (Mason et al. 2013). How Rok kinase leading to Myo-II medioapical accumulation is molecularly localized under the control of Snail and Twist transcription factor expression remains unknown today. Simulations taking into account the elastic and 
hydrodynamic flow responses of the cytoplasm to mesodermal apical actomyosin contraction successfully phenocopy mesoderm invagination (Pouille \& Farge 2008, He et al. 2014).

\section{Planar Myo-II Anisotropy}

Besides invagination, another master movement driving morphogenesis is tissue elongation and narrowing, or convergent extension. Convergent extension is most often generated by cell intercalation, a specialized directed movement whereby a cell inserts itself between two neighboring cells, thereby decreasing the width of the tissue in the direction of cell movement and increasing its length in the perpendicular direction (Keller et al. 2000). In Drosophila embryos, this intercalation is again the result of anisotropic, intracellular Myo-II distribution. In this case, the anisotropy is organized in the apical plane of the ventrolateral cells, at the level of the adherens junctions. Cell junctions parallel to the dorsoventral axis contain higher concentrations of Myo-II than perpendicular junctions (i.e., those parallel to the anteroposterior axis) (Figure 1e) (Bertet et al. 2004). The junctions parallel to the dorsoventral axis, which are enriched with Myo-II, contract, thereby intercalating individual cells between anterior-posterior neighboring cells in a dorsoventral manner (Figure 1e). Anisotropic Myo-II contraction of cell junctions can also lead to the formation of multicellular, contractile rosette structures (Blankenship et al. 2006). Myo-II planar polarity is regulated by anteroposterior patterning genes that enrich junctions parallel to the anteroposterior axis with Par-3. This prevents apical accumulation of Myo-II and is regulated by striped patterns of Toll receptors (Bertet et al. 2004, Pare et al. 2014). In addition to intercalation, cell elongation, possibly resulting from mesoderm invagination, participates in convergent extension (Butler et al. 2009).

\section{Actomyosin Cables and Boundary Stabilization}

Anisotropic distribution of Myo-II is involved not only in the generation of morphogenetic movements but also in the maintenance of stable physical boundaries between multicellular domains that are characterized by the expression of different patterning genes. This is the case for Drosophila embryo segmentation domains. For example, a Myo-II cable is formed at the boundary between the Wingless and Engrailed domains. This cable leads to actomyosin-driven line tension that prevents deformation of the boundary and mixing of the two types of differentiated cells during development (Landsberg et al. 2009, Monier et al. 2010). The same principle underlies the maintenance of dorsoventral compartments during tissue growth in the wing imaginal disk of the Drosophila embryo larvae (Aliee et al. 2012). Although differences in the expression of patterning genes are suspected to drive apical accumulation of Myo-II in junctions at boundaries, the underlying molecular mechanisms that sense differential expression and translate this input into Myo-II distribution remain to be discovered.

\section{MECHANOTRANSDUCTIVE, MORPHOGENETIC REGULATION OF MYO-II ANISOTROPY AND TISSUE GROWTH}

\section{Mechanotransductive Cues in the Establishment of Myo-II Apicobasal Polarity}

The mechanisms leading to epithelial invagination in Drosophila involve the apically polarized secretion of the signaling protein Fog, whose expression is induced by the mesoendodermal gene product Twist. Downstream, Fog activates a Rho pathway, leading to medioapical accumulation of Myo-II (Dawes-Hoang et al. 2005). Fog expression alone is not sufficient to trigger medioapical accumulation of Myo-II and mesoderm invagination. It requires the expression of Snail (Morize et al. 1998, Pouille et al. 2009, Seher et al. 2007). However, this requirement for Snail cannot be understood in terms of purely biochemical interactions between the Snail and Fog pathways, as 

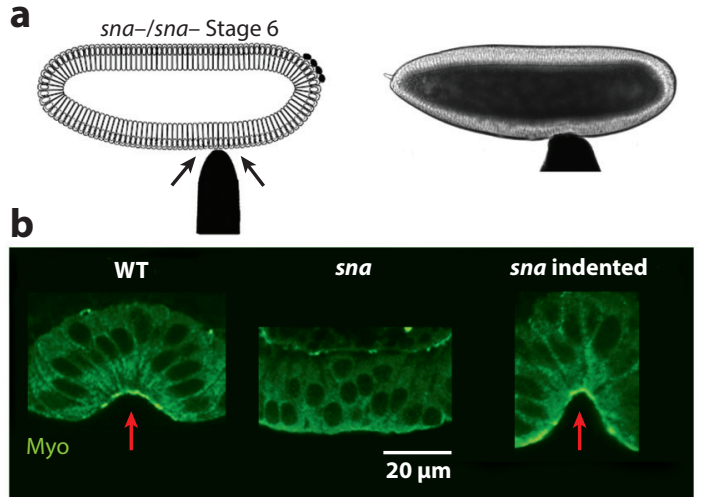

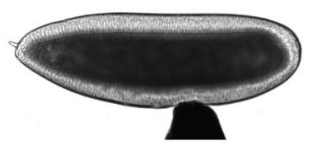

$\overline{20 \mu m}$

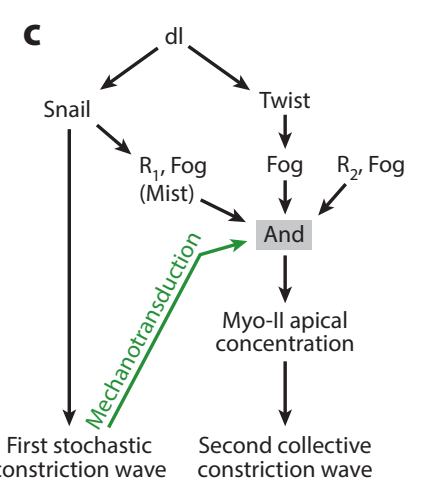

constriction wave constriction wave d

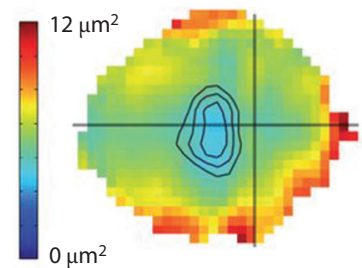

$\mu \mathrm{m}^{2}$

Figure 2

(a) Softly indenting Drosophila snail (sna) mutant embryos defective in the apical accumulation of nonmuscle myosin-II (Myo-II) and mesoderm invagination $(b)$ rescues the wild-type (WT) phenotypes of apical accumulation of Myo-II and mesoderm invagination (for original RVB figures, see Pouille et al. 2009). (c) The mechanogenetic network regulating mesoderm invagination, established by Dorsal (dl), is implemented with the Fog receptor Mist, which acts downstream of Snail (Manning et al. 2013), and another putative receptor of Fog, $\mathrm{R}_{2}$, which is homogenously expressed. This network is required for the apical accumulation of Myo-II in response to both ectopic expression of Fog in the ectoderm (Dawes-Hoang et al. 2005) and mechanical indentation of sna $a^{-}$embryos in the mesoderm (Pouille et al. 2009). (d) Gradient of cell shape (apical cell area) in the growing wing disc of the Drosophila embryo. Cell shape differences potentially regulate cell growth via mechanotransductive signals (adapted with permission from Legoff et al. 2013).

artificial ectopic expression of Fog generates apical accumulation of Myo-II in ectodermal domains, which do not express Snail (Dawes-Hoang et al. 2005). The existence of a mechanotransductive interaction between the two pathways reconciles these puzzling observations. Snail expression leads to the transient apical nucleation of Myo-II, which generates apex pulses of mechanical constriction (Martin et al. 2009). If the pathway downstream of Fog can be mechanically activated, then Snail-dependent mechanical apical pulses may be required to activate medioapical accumulation of Myo-II downstream of Fog. As a consequence, the resulting mesoderm invagination would stretch the lateral neighboring ectodermal cells. If Fog is artificially expressed ectopically, this could thus mechanically activate the Fog-dependent apical accumulation of Myo-II in the ectoderm, even in the absence of Snail expression. Indeed, softly indenting the mesoderm in snail (sna) mutants rescues both the apical accumulation of Myo-II and mesoderm invagination characteristic of the wild type, in a Fog-dependent process (Figure 2a,b) (Pouille et al. 2009). This suggests that apical accumulation of Myo-II and subsequent mesoderm invagination are mechanically induced by Snail-dependent apical pulsations in a Fog-dependent mechanotransductive process. The plausibility of this hypothesis is reinforced by mechanotransduction-based simulations that quantitatively phenocopy the dynamics of experimental apical constriction (Bouclet et al. 2011), as well as by the finding of a twist-dependent increase in the probability of having stable apex constriction in the cells neighboring already constricting cells (Xie \& Martin 2015) (Figure 2c). This is potentially reminiscent of the hyperrestoration theoretical proposal of active mechanical reaction of cells against deformation in amphibian embryos during morphogenesis (Beloussov et al. 1975, Odell et al. 1981). Such a mechanotransduction process is proposed to trigger the efficient coordinated constriction of mesoderm apexes required for invagination, as mechanical strains propagate rapidly and at a long distance across tissues, possibly leading to autosynergic mechanical activation of collective constriction through all the Fog-expressing mesoderm (Bouclet et al. 2011). 


\section{Mechanotransductive Maintenance of Myo-II Junctional Planar Polarity}

Mechanical stabilization of polarized Myo-II in the apical plane also occurs in ectodermal junctions. Gentle pipette aspiration of the ectodermal cell apex enhances apical accumulation of junctional Myo-II during Drosophila embryo convergence-extension (Fernandez-Gonzalez et al. 2009). This suggests that a mechanical positive feedback loop drives auto-reinforcement (or maintenance) of the planar polarity of Myo-II in response to the convergence-extension triggered by polarized Myo-II. In this specific case, junctional stabilization of Myo-II could result from an increase in the biochemical affinity of Myo-II for actin under mechanical stress, as suggested by the in vitro work of Spudich (2006). Mechanical stabilization of junctional Myo-II appears to be exploited at different stages of embryonic development and in different species. For instance, muscle activity in C. elegans embryos transmits forces to the epithelium across desmosomal junctions. This has been suggested to stabilize Myo-II in the stress fibers surrounding the epidermis, thereby leading to radial contraction of the epithelium contributing to elongation of the embryo by $25 \%$ (Zhang et al. 2011). Apoptosis and, more specifically, apoptotic constricting forces play a major role in morphogenesis (Tokoyama et al. 2008). They may also mechanically activate apical accumulation of Myo-II in junctions, although a role for biochemical signals generated from apoptotic cells cannot yet be excluded (Monier et al. 2015). Myo-II mechanosensitivity was also suggested to act in epithelial tissues during organogenesis in Drosopbila (Bardet et al. 2013) and in chick (Filas et al. 2011). Mechanotransductive feedback processes are also involved in plant development, in which mechanosensitive microtubule reorganization regulates meristem shaping and coordinated cell growth via Katanin (Hamant et al. 2008, Uyttewaal et al. 2012). Overall, the mechanosensitivity of Myo-II activity participates in both embryonic morphogenetic development and the maintenance of the established embryonic biomechanical morphology, which, in the absence of such reactive mechanical induction of active tension, could be lost within a few hours by passive cell rearrangements that relax tensions.

\section{Mechanotransductive Feedback in Tissue Growth Regulation}

In cell culture, cell proliferation was long suspected to be regulated by the mechanical strains developed by cell packing based on the common observation that cells downregulate their cell division rate when getting condensed, reaching confluence (Ukena et al. 1976). Quantitative control of cell shape by adhesion and micropattern control parameters confirmed its regulatory role (Zhu \& Assoian 1995, Huang \& Ingber 2000), with the involvement of p27 as a premitotic inhibitor (Chassot et al. 2008).

In vivo, cell compression inhibiting cell division has also been theorized to be at work during tissue growth (Shraiman 2005). In the growing wing imaginal disc of Drosophila, cells in the center of the wing pouch have a smaller and more isotropic apical surface than cells in the periphery, which are larger and elongated tangentially (Legoff et al. 2013, Mao et al. 2013) (Figure 2d). Laser ablation experiments have revealed that the tension along cell-cell contacts is also greater for cells in the periphery than for cells in the center, suggesting that cells in the center are compressed (Legoff et al. 2013, Mao et al. 2013). Additionally, peripheral cells show higher tension along longer, tangential cell-cell contacts than along shorter, radial ones, which indicates that these cells are being stretched, probably by the increased cell density in the center of the wing pouch. Measurements of mechanical stress distribution using photo elasticity support these findings (Nienhaus et al. 2009). Moreover, cells in the periphery exhibit actin-myosin cables spanning several cells in a tangential orientation (Legoff et al. 2013), indicating mechanical induction of actin-fiber assembly (Fernandez-Gonzalez et al. 2009). Therefore, during tissue growth, cells in 
the center may become more and more compressed and may therefore stop dividing in response to repressive mechanotransduction signals (Hufnagel et al. 2007). In Drosophila egg chambers, epithelial cells at the periphery also become stretched by the growth of internal germ line cysts. This enhances apical stabilization of Myo-II, leading to an increase in the resistance of epithelial cells to growth (Wang \& Riechmann 2007).

Interestingly, the Hippo pathway, which has been implicated in tissue growth control in Drosophila and vertebrates, is active during wing disc growth (Dong et al. 2007, Harvey et al. 2013, Oh \& Irvine 2008). The Hippo pathway translates the stiffness of a substrate into regulation of cell proliferation by controlling the nuclear localization of the mitogenic transcription factor Yorkie. Soft matrices and dense cell populations have both been shown to activate the Hippo pathway, resulting in the exclusion of Yorkie from the nucleus and the suppression of cell proliferation; by contrast, inhibition of the Hippo pathway resulting from stiff matrices or low-density cell populations leads to nuclear translocation of Yorkie and to cell proliferation (Aragona et al. 2013, Dupont et al. 2011, Zhao et al. 2007). Furthermore, the formation of actomyosin stress fibers may play an important role in this process, possibly by sequestering activators of the Hippo pathway such as Amot, thus leading to cell proliferation (Dupont et al. 2011, García Fernández et al. 2011, Wada et al. 2011, Zhao et al. 2012). Therefore, compression of cells could inhibit cell proliferation as a result of few or no stress fibers being present, whereas the formation of stress fibers could lead to the nuclear translocation of Yorkie and to cell proliferation. Interestingly, ectopic expression of the formin Diaphanous or depletion of actin-capping proteins induces overgrowth in the wing disc by promoting nuclear accumulation of Yorkie (García Fernández et al. 2011, Sansores-Garcia et al. 2011). However, whether Yorkie is directly responsible for inducing cell proliferation via stretching in the wing disc is unclear, as is whether the observed actin fibers play a role in the nuclear translocation of Yorkie in the peripheral cells of the wing disc. The relationship between mechanical strain and the cell cycle in the wing disk remains an open question be answered experimentally.

\section{MECHANOTRANSDUCTIVE, MORPHOGENETIC REGULATION OF EMBRYONIC TISSUE DIFFERENTIATION}

\section{Mechanotransduction in the Differentiation of Cultured Cells}

The study of mechanotransduction in cell and tissue reorganization in response to environmental, mechanical strains was initiated in vitro. It was motivated by the structural response of cells and tissues (e.g., cytoskeleton rearrangement, cell division) to the mechanical strains associated with blood flow or pathological fibrotic rigidity (Bershadsky et al. 2003, Ghajar \& Bissell 2008, Gospodarowicz et al. 1978). The regulation of cell differentiation by mechanical strains has been demonstrated in vitro. One mechanism demonstrates that the mechanical tension of plasma membranes can modulate differentiation by inhibiting the endocytosis of signaling proteins via membrane flattening (Rauch et al. 2002). In C2C12 mouse cells, the mechanical inhibition of BMP2 endocytosis prevents the release of BMP2 from its receptor in acidic early endosomes, which leads to enhanced signaling, acceleration of the nuclear translocation of the transcription factor Smads, and expression of the target gene junB, inducing myoblastic-osteoblastic transdifferentiation. Such regulation of transdifferentiation, mediated by mechanical modulation of endocytosis (Rauch \& Farge 2000, Raucher \& Sheetz 1999), could also trigger myoblastic-osteoblastic transdifferentiation in $\mathrm{C} 2 \mathrm{C} 12$ cells exposed to concentrations of BMP2 that are insufficient to induce differentiation without mechanical strain (Rauch et al. 2002). 
A similar mechanotransductive mechanism based on mechanical inhibition of endocytosis is proposed to underlie the activation of the Fog pathway, which leads to Drosophila mesoderm invagination (see above). In this case, Fog endocytosis is blocked by the apical membrane tension proposed to be generated by Snail-dependent apical pulsations (Pouille et al. 2009). Membrane tension-dependent mechanotransduction is probably modulated by many additional factors, dependent on biological context. For example, caveolae are proposed to generate a reservoir of membrane that is able to modulate any membrane tension-dependent mechanotransduction process (Nassoy \& Lamaze 2012).

In addition to mechanical strain applied to cells, the cell shape itself induces stem cell differentiation in vitro. Round human mesenchymal stem cells spontaneously differentiate into adipocytes, whereas adherent, flattened stem cells differentiate into osteoblasts, indicating a signaling role for either shape or mechanical interaction with the substrate in stem cell differentiation (McBeath et al. 2004). Mechanical control of differentiation by substrate stiffness has been found in naïve mesenchymal stem cells: neuron differentiation was observed for soft, $1 \mathrm{kPa}$ substrates; myoblast differentiation for intermediate, $10 \mathrm{kPa}$ substrates; and osteoblastic differentiation for $100 \mathrm{kPa}$, rigid substrates (Engler et al. 2006).

\section{Mechanical Induction of Embryonic Patterning and Differentiation In Vivo}

In vivo, mechanical strain resulting from the morphogenetic movements of early embryogenesis leads to mechanical induction of cell differentiation. Results from mechanical, genetic, optical (nonlinear photoablation), and physical (magnetic) tools have demonstrated mechanical induction of the expression of the mesoendodermal transcription factor Twist in response to convergenceextension cell movements (Figure 3a) (Desprat et al. 2008, Farge 2003). This mechanotransductive enhancement of Twist expression is vital for anterior midgut differentiation in the future anterior endoderm of early Drosophila embryos. Here, a Src42A-dependent mechanotransductive process activates the $\beta$-catenin ( $\beta$-cat) pathway, triggering the partial release of $\beta$-cat from cell junctions and leading to $\beta$-cat nuclear translocation and Twist expression (Desprat et al. 2008). Interestingly, mechanical cues were also found to play a role in the developmental genetic program of early mouse embryos. Mechanical strains developed by uterine tissue constraints on early mouse embryos were proposed to regulate distal visceral endoderm developmental gene expression and development (Hiramatsu et al. 2013).

The mechanical activation of $\beta$-cat appears to be conserved in other developmental processes, as it is also found in the response of bone joints to spontaneous muscle activities during mouse development (Figure 3b) (Hens et al. 2005, Kahn et al. 2009). In this case, mechanical loading maintains the tissue in a pluripotent state, preventing osteoblastic differentiation and bone fusion during development.

Mechanotransduction regulates development from earliest embryogenesis to organogenesis. For instance, RhoA-dependent mesenchymal cell compaction induces the odontogenic differentiation involved in tooth formation (Mammoto et al. 2011). Mechanical cues are also required for the reconstitution of proper lung tissue development ex vivo (Huh et al. 2010). In vivo, $k l f 2 a$-dependent hemodynamic forces drive valve formation in zebrafish heart formation (Figure 3c) (Hove et al. 2003, Vermot et al. 2009). Neural crest specification may be regulated by Myo-II-dependent cell shape changes (Kim et al. 2014), and mitosis waves in early Drosophila embryo syncytium are potentially generated by mechanotransductive excitable waves (Idema et al. 2013).

In addition to its mechanosensitive role in the anterior endoderm in Drosophila embryos, the $\beta$-cat pathway maintains high levels of Twist in the Drosophila embryo mesoderm. Here, the 

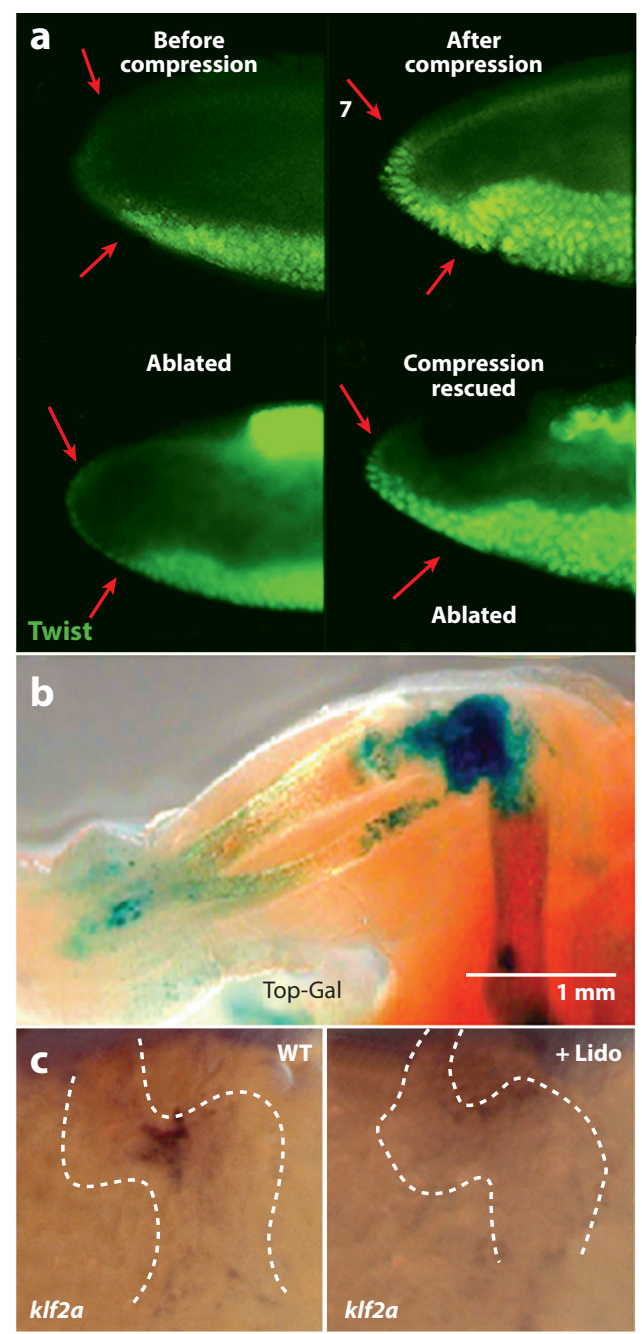

Figure 3

(a) Dorsal photoablation prevents the compression of the anterior pole of the gastrulating Drosopbila embryos that results from convergent extension, inhibiting Twist expression in the anterior endoderm (between red arrows). Enhanced Twist expression is rescued by magnetic forces that quantitatively mimic compression in vivo (for original RVB figures, see Desprat et al. 2008). (b) $\beta$-Galactosidase (Top-Gal) expression as a marker of $\beta$-catenin ( $\beta$-cat) signaling resulting from muscle pulsatile activity during mouse joint development in vivo (adapted with permission from Hens et al. 2005; Kahn et al. 2009). (c) klf2a expression induced by reverse hydrodynamic flow is downregulated after lidocaine (lido) treatment decreasing heart rate and is required for zebrafish heart valve formation (adapted from Vermot et al. 2009, published under a CC-BY license). Abbreviation: WT, wild type.

mechanical strain of mesoderm invagination induces phosphorylation of $\beta$-cat at its E-cadherin binding site (Y654 in mouse, Y667 in Drosophila) by Src42A (Brunet et al. 2013). Phosphorylation of the Y654- $\beta$-cat site leads to an $80 \%$ loss of affinity between $\beta$-cat and E-cadherin at cell junctions (Roura et al. 1999). The mechanical activation of Y654- $\beta$-cat is thus proposed as the initial mechanotransductive cue leading to the release of a pool of $\beta$-cat from the junctions, thereby allowing its nuclear translocation and the expression of the twist target gene. Strikingly, 
the Src-family kinase-dependent mechanical activation of Y654- $\beta$-cat phosphorylation is also required for mesoderm specification in a vertebrate: the zebrafish. Here, Y654- $\beta$-cat phosphorylation leads to the expression of notail (the zebrafish brachyury ortholog) in margin cells stretched in response to the first epiboly movements in zebrafish development during the dome stage (Figure 4a-d) (Brunet et al. 2013).

\section{MECHANOTRANSDUCTION IN THE COURSE OF EVOLUTION}

\section{Mechanotransduction in Key Evolutionary Transitions in Animals}

The origin of mesoderm, which dates back to the first bilaterian animals more than 570 million years ago, remains one of the most important questions in the field of evolutionary developmental biology. This uncertainty results, in part, from the lack of conserved biochemical signals found upstream of $\beta$-cat-dependent mesoderm differentiation in vertebrates. Additionally, no evidence had surfaced before Brunet et al.'s (2013) finding that $\beta$-cat is involved in mesoderm differentiation in the nonvertebrate superphylum Ecdysozoa, to which insects such as Drosophila belong. Together, however, the conservation in Drosophila and zebrafish, which diverged directly from the first bilaterians, of the same mechanotransductive process of phosphorylation at the same Y654 site in response to the very first morphogenetic movements of embryogenesis and the finding that $\beta$-cat is involved in mesoderm differentiation in an ecdysozoan strongly suggest that $\beta$-catdependent mechanical induction was a mesoderm inducer in the last bilaterian common ancestor (Brunet et al. 2013).

If mechanically induced Y654- $\beta$-cat phosphorylation was involved in the origin of the mesoderm, one would expect this site to be ancestral for bilaterians. Indeed, this specific site is conserved in the $\beta$-cat sequence of all bilaterian genomes examined and, in fact, of all animal genomes, including sponges (with exception of ctenophores, whose phylogenic position is still unknown) (Figure 4e). As all of these genomes also possess the other actors involved in the mechanosensitive $\beta$-cat pathway, such as Src family kinases and E-cadherins (Nichols et al. 2012, Suga et al. 2013), mechanically induced $\beta$-cat translocation may date to the last common metazoan ancestor. This pathway would then have been co-opted for mesoderm induction in the first bilaterians.

What could have been the function of the mechanosensitive $\beta$-cat pathway before the mesoderm emerged? In the blastula-like, spherical colonies ancestral to animals, $\beta$-cat may have originated as a sensor of junction stretching (Brunet et al. 2013). If we assume, like many authors (Arendt 2004, Haeckel 1874, Nielsen, 2012, Wolpert 1992), that early animal evolution then went through an invaginating, gastrula-like stage (the gastraea), this response to stretching would have been automatically activated at the margin of the primitive blastopore, where cells are pulled by their invaginating, apically constricting neighbors. Secreted Wnt ligands would then have evolved to establish and consolidate marginal cell identity, as they do in later stages of development in zebrafish (Brunet et al. 2013). Other signaling proteins would have later complemented this pathway in a lineage-specific fashion, such as Dorsal for early mesoderm induction in Drosophila (Brunet et al. 2013).

Before contributing to the emergence of the first bilaterians through mechanical induction of the mesoderm, mechanotransduction may have already played a role in the emergence of the first animals. Indeed, as already mentioned and as first proposed by Haeckel, the evolutionary transition from a cell colony, the blastula, to a gastrulating organism, the gastraea, is often assumed to have led to the emergence of the probable first organ: the gut (Haeckel 1874, Jaegerstem 1956, Wolpert 1992). A necessary physical condition for gastrulation is the generation of a difference in surface area in thick tissues (Bozic et al. 2006). As we saw earlier, in early Drosophila embryos, 


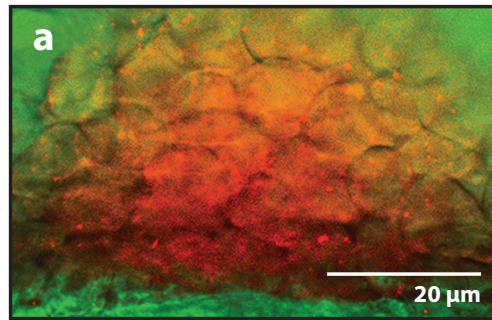

Fluorescent ultra magnetic liposomes

Blebbistatin + UML

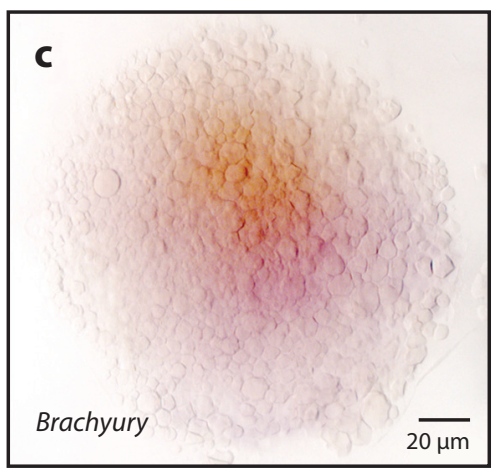

$\beta$-catenin sequence evolution

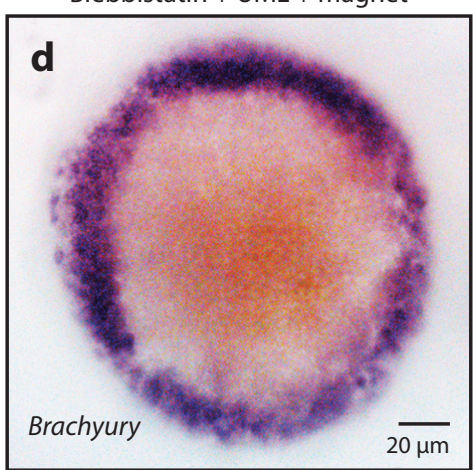

e

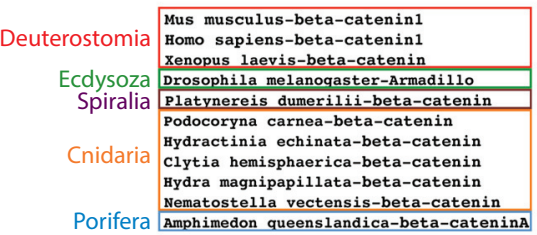

Mus musculus-beta-catenin

ytia hemisphaerica-beta-cateni

rematostella vectensis beta-caten in

Porifera Amphimedon queenslandica-beta-cateninA

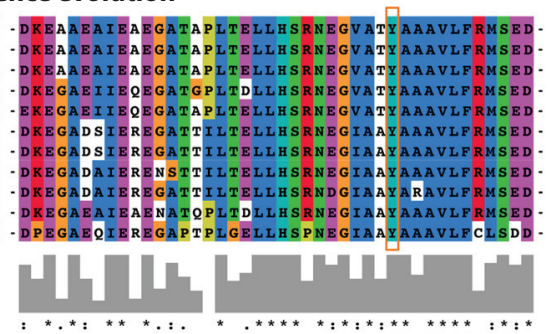

Figure 4

Blebbistatin inhibition and magnetic rescue of initiation of epiboly. (a) Loading fluorescent ultramagnetic liposomes (UMLs) into zebrafish embryos in which epiboly has been blocked by blebbistatin treatment (b) allows magnetic rescue of epiboly morphogenetic movement initiation, $(c, d)$ rescuing the mesodermal expression of Brachyury ( $\mathrm{Bra}$ ) that is lacking in epiboly-defective embryos in vivo (Brunet et al. 2013).

(e) Conservation of the Y654 site of $\beta$-catenin ( $\beta$-cat), whose mechanosensitive phosphorylation regulates $\beta$-cat release from junctions to the cytoplasm, allowing nuclear translocation and expression of mechanotransductive mesoderm target genes. An alignment of $\beta$-cat protein sequences from representatives of the main animal phyla (obtained from UniProt) is shown. Colors reflect chemical properties of amino acids, following ClustalX 2.1 conventions. Asterisks, colons, and periods indicate single, fully conserved residues or groups of residues with strongly or weakly similar properties, respectively. Gray bars denote the ClustalX conservation scores for each column, ranging from 100 (fully conserved) to 0 (not conserved). 
this difference can be simulated by indenting blastula-like sna mutant embryos, resulting in the mechanical activation of gastrulation in a Myo-II-dependent process (Pouille et al. 2009). This had led to postulation that Myo-II-dependent invagination was mechanically induced in primitive organisms by contact with the sea bottom or via sea hydrodynamics constraints such as streams or waves, for instance. This response, which could have functioned for feeding, might have existed at the origin of gastrulation as a feeding response to touch in multicellular tissues, a primitive feature having conditioned most ancient animals' emergence (Farge 2003, Pouille et al. 2009).

\section{The Mechanotransductive Pathways and Their Phylogeny}

The molecular mechanisms underlying mechanotransduction are based on the soft-matter properties of the biological structures that biochemically regulate cell and tissue physiological functions. Soft-matter structures are characterized by structuring energies on the order of $10 \mathrm{kT}$ (10 times Brownian molecular energy), sufficient to maintain a structure resistant to Brownian motion but low enough to be efficiently modified by biochemical interactions with molecular partners. Such soft-matter low-structuring-energy levels additionally confer inherent high deformability properties to biological structures. However, the high biochemical activities of biological structures depend critically on their physical shape or conformation. This makes biological structure and associated biochemical activities highly reactive to mechanical stresses, namely constitutively mechanosensitive. This is the case for endocytotic vesicle buds, whose characteristic energy is approximately $10 \mathrm{kT}$ (Jin \& Nossal 2000) and whose flattening is thus highly sensitive to membrane tension (Nassoy \& Lamaze 2012, Rauch \& Farge 2000, Raucher \& Sheetz 1999). This allows, as we saw, mechanotransduction to result from the mechanical modulation of endocytosis (Pouille et al. 2009, Rauch et al. 2002). A priori, similar reasoning applies to any protein physically associated with a scaffolding structure of the cell, from ion channels whose opening has long been known to be regulated by membrane tension (Chalfie 2009) to adhesion and junctional proteins, whose biochemical activity changes in response to tension-induced conformational changes. Talin and $\alpha$-catenin conformational changes, for example, lead to junction reinforcement (del Rio et al. 2009, Geiger et al. 2009, Grashoff et al. 2010, Riveline et al. 2001, Yonemura et al. 2010). Interestingly, the mechanically induced conformational change of p130Cas in focal adhesions leads to the opening of the protein's phosphorylation site to Src (if active), thereby allowing its phosphorylation and the activation of the downstream p38/MAPK pathway (Sawada et al. 2006). In addition to integrin-associated scaffold proteins, E-cadherins, which are mechanically linked to $\beta$-cat, are under actomyosin tension (Borghi et al. 2012). Both integrin and E-cadherin junctions link the mechanical environment of the cell with the nucleus (Wang et al. 2009), potentially modulating the transcription state of the genome through chromatin conformational changes (Shivashankar 2011, Swift et al. 2013).

In a cellular context, any polarized animal cell (for example, an epithelial cell) possesses three potential external mechanoreception sites (Figure 5a): its apical membrane (apical field), intercellular

\section{Figure 5}

(a) Apicobasal organization of external mechanosensory fields. (b) Phylogeny of the external mechanosensory fields. Note that TRP channels have been lost in land plants but are present in green algae. $(c)$ Conservation of the $\beta$-catenin GSK3 target sites regulating cytoplasmic $\beta$-catenin degradation. Colors reflect chemical properties of amino acids, following ClustalX 2.1 conventions. Asterisks, colons, and periods indicate single, fully conserved residues or groups of residues with strongly or weakly similar properties, respectively. Gray bars denote the ClustalX conservation scores for each column, ranging from 100 (fully conserved) to 0 (not conserved). 


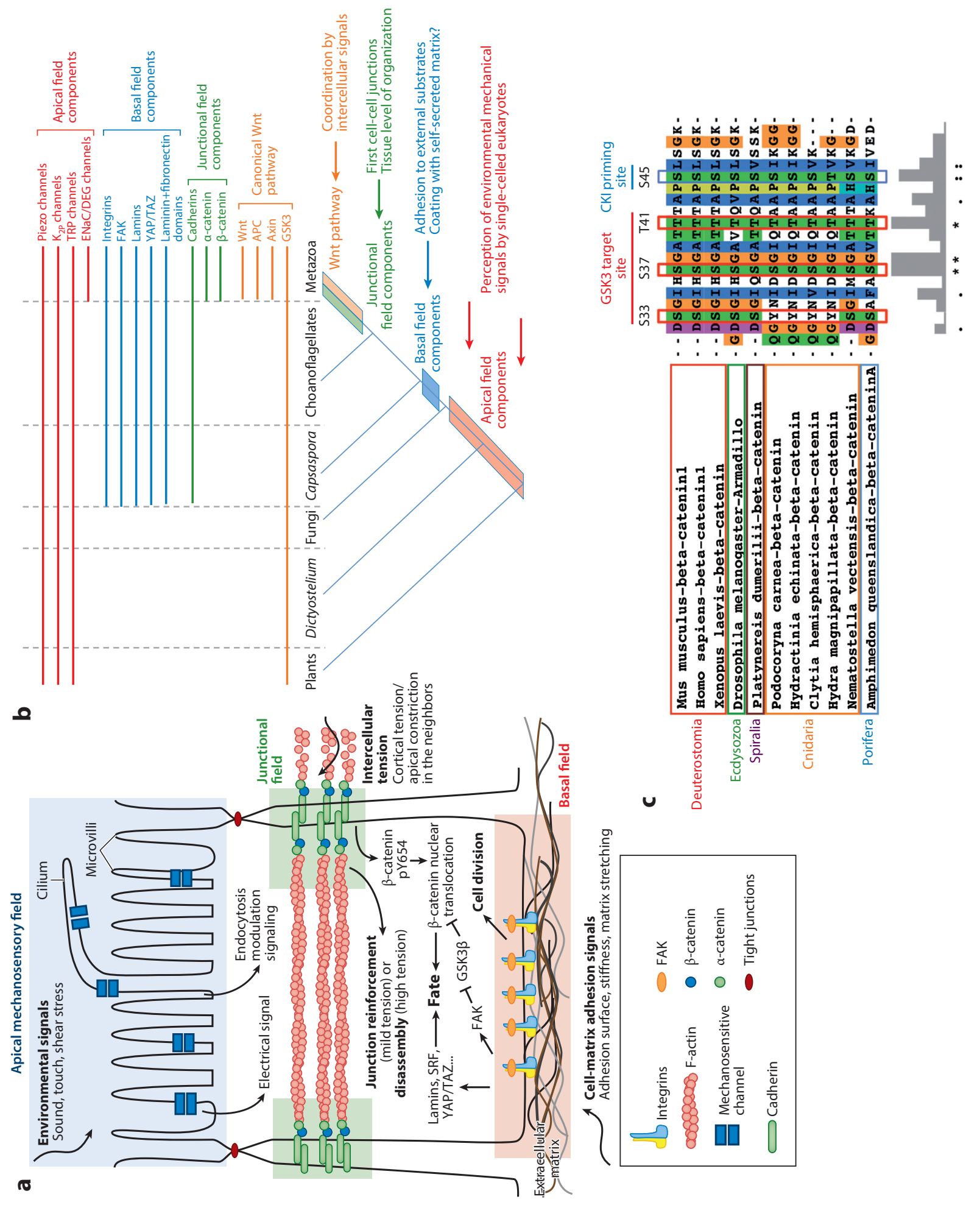


junctions (junctional field), and basal adhesion surface to the extracellular matrix (basal field). These sites specialize in receiving distinct types of mechanical signals. The apical field is ideally located to perceive environmental signals, including compression/dilation waves such as sound and shear stress resulting from liquid flow. The junctional field predominantly perceives the deformation of neighboring cells, apical constriction being one example. Finally, the basal field perceives mechanical properties of the extracellular matrix, either static (stiffness) or dynamic (stretching).

In line with its specialization, each field expresses distinct mechanosensitive proteins (Figure 5a). In animals, mechanosensory cells involved in hearing, touch, proprioception, and graviception rely on a specialized apical field that often expands into dendritic trees, cilia, or microvilli (Chalfie 2009). This field expresses mechanosensitive ion channels, including members of the TRP, DEG/ENaC, and $\mathrm{K}_{2 \mathrm{P}}$ families (reviewed in Chalfie 2009). Another family, Piezo (Coste et al. 2010, 2012), transduces shear stress in the vascular endothelium (Li et al. 2014) and is involved in touch (Ranade et al. 2014). Junctional mechanotransduction operates in a dual fashion. Mild tension strengthens junctions, notably by promoting catenin-actin binding and vinculin recruitment (Buckley et al. 2014, Kris et al. 2008, Leckband et al. 2011, Liu et al. 2010, Papusheva \& Heisenberg 2010, Yonemura 2011, Yonemura et al. 2010). However, high tension promotes junction disassembly (Buckley et al. 2014), which, as we saw, is proposed to release $\beta$-cat in the presence of activated Src-type kinases that phosphorylate $\beta$-cat at its cadherin-binding site (Y654 in mice, Y667 in Drosophila melanogaster). This, in turn, prevents cadherin from rebinding (Daugherty \& Gottardi 2007) and stimulates $\beta$-cat transcriptional activity (Veelen et al. 2011) in response to stretching (Brunet et al. 2013, Desprat et al. 2008, Whitehead et al. 2008). Finally, basal mechanotransduction activates many pathways, including cell division in response to stiffness and activation of the focal adhesion kinase (Fak) in response to a broad adhesion surface (Pirone et al. 2006). More recently, control of cell fate by substrate stiffness has been shown to act through lamins (Swift et al. 2013), YAP/TAZ (Yes-associated protein and transcriptional coactivator with PDZ-binding motif) (Dupont et al. 2011), and SRF (Connelly et al. 2010). Moreover, via GSK3 inhibition, the basal field can, like the junctional field, mechanically activate canonical Wnt signaling (Samuel et al. 2011) independently of the YAP/TAZ pathway (Benham-Pyle et al. 2015).

The three mechanosensory fields of animal cells do not only perceive different signals and activate different pathways, they also originated at different times. The apical pathway is the most ancient: Perception of environmental mechanical signals is widespread in single-celled eukaryotes (Anderson 1989), and most of the proteins involved originated with opisthokonts (the group containing the last common ancestor of Fungi and Animalia, and all its descendants) or even earlier (Figure $5 \boldsymbol{b}$ ). Most proteins of the basal pathway can be traced back to the closest single-celled relatives of animals: choanoflagellates and Capsaspora (Figure 5b) (King et al. 2008, Sebé-Pedrós et al. 2010, Suga et al. 2013). Together with animals, they form the group Holozoa. The basal pathway may have originated for adhesion to inorganic substrates, which is known in these single-celled organisms to modulate differentiation and division (Figure $5 \boldsymbol{b}$ ).

Moreover, because the genomes of these groups also encode metazoan-type extracellular matrix domains (King et al. 2008, Suga et al. 2013, Williams et al. 2014), holozoan ancestors could likely embed themselves in a self-secreted matrix, possibly consolidating adhesion. Finally, most components of the junctional pathway (catenins and conventional cadherins) and of the canonical Wnt pathway originate with animals (Figure $5 \boldsymbol{b}$ ). The only two exceptions are unconventional cadherins, which are present in all Holozoa (Nichols et al. 2012) and may contribute to facultative colony formation in Capsaspora and choanoflagellates (Dayel et al. 2011, Sebé-Pedrós et al. 2013), and GSK3, present in all eukaryotes (Table 1). Comparative data from plants, yeasts, slime molds, and animals suggest that GSK3 functions as an ancient orchestrator of a pan-eukaryotic stress response that inhibits mitosis and promotes meiosis/sporulation (Table 1). Thus, stiffness-induced 
Table 1 Functions of GSK3 across the eukaryotic tree of life

\begin{tabular}{l|l}
\hline Taxa & \multicolumn{1}{c}{ GSK3 function } \\
\hline Arabidopsis thaliana (plants) & Stress response: starvation \\
& Mitosis and growth inhibition \\
& Organogenesis: flower development, notably formation of the \\
& megaspore mother cell (which undergoes meiosis to produce the \\
& female gametophyte) (Saidi et al. 2012) \\
\hline Dictyostelium discoideum (slime mold) & Spore formation (Schilde et al. 2004) \\
\hline Saccharomyces cerevisiae (yeast) & Four paralogs: mck1, rim11, mrk1, and ygk3 \\
& Stress response: glucose and nitrogen depletion; UV, ionic, and \\
& osmotic stress \\
& Mitosis inhibition \\
& Meiosis/sporulation (Bowdish et al. 1994, Brazill et al. 1997, \\
& Hirata et al. 2003, Kassir et al. 2006, Neigeborn \& Mitchell 1991) \\
\hline Metazoa & Mitosis inhibition and metabolism shutdown (Bechard \& Dalton \\
& 2009, Mao et al. 2009, Ohteki et al. 2000, Tseng et al. 2006) \\
& Gametogenesis (Guo et al. 2003, Kalamegham et al. 2007, \\
& Rentzsch et al. 2005) \\
\hline
\end{tabular}

GSK3 inhibition may have contributed to mitosis stimulation in response to adhesion in holozoan ancestors. Consistent with this hypothesis, stiffness inhibits GSK3 through the basal pathway via Fak and Akt (Samuel et al. 2011); reciprocally, GSK3 inactivates YAP/TAZ (Azzolin et al. 2014), a basal pathway-activated mitogen (Aragona et al. 2013). Genomic data suggest that this crosstalk between GSK3 and the basal field dates back to unicellular holozoans, as all components are present in the choanoflagellate and Capsaspora genomes.

\section{HYPERPROLIFERATION AND INCREASED STIFFNESS IN TUMOR DEVELOPMENT MECHANICALLY REACTIVATES EMBRYONIC ß-CATENIN-DEPENDENT DEVELOPMENTAL PATHWAYS}

Our understanding of tumor progression has progressed considerably as a result of intensive biochemical and genetic studies of the pathways and master genes involved in the deregulation of tissue homeostasis (Hanahan \& Weinberg 2011). The role of the microenvironment in tumor progression and invasion is being intensively studied (Bissell \& Radisky 2001). Within this context, pioneering approaches have implicated the fibrotic rigidity of the tumor microenvironment in enhancing late-stage tumor progression (Butcher et al. 2009, Ghajar \& Bissell 2008, Wozniak \& Chen 2009). This increase in rigidity may be characterized by an anomalous boost of actomyosin activity in cells adapting to the fibrotic microenvironment. Increased actomyosin activity is believed to activate mechanotransduction pathways as a result of the local increase in tension applied to cell junctions, particularly adherens junctions, possibly leading to subsequent cytoskeleton reorganization (Butcher et al. 2009, Ghajar \& Bissell, 2008, Grashoff et al. 2010, Sawada et al. 2006). Following these results, a cascade of studies has focused on the role of the microenvironment in tumor progression from the nanoscale level to the tissue level. The evolving extracellular matrix, the scaffold for tissue organization, provides both biochemical and biomechanical signals that modulate tissue development and homeostasis and, when altered, critically influence tumor evolution (DuFort et al. 2011, Pickup et al. 2014, Yu et al. 2011). For example, the oncogenic mechanical engagement of vinculin enhances PI3-K activation of phosphatidylinositol (Rubashkin et al. 2014). Most recently, a 3D substrate with low stiffness was shown to 
regulate the self-renewing capabilities of tumor-initiating cells, with $\mathrm{H} 3 \mathrm{~K} 9$ demethylation leading to Sox 2 expression, indicating the deregulation of cell differentiation in response to low-rigidity conditions (Tan et al. 2014). Low stiffness also enhances ovarian cancer metastasis through a mechanosensitive Rho-Rock-dependent process in vitro (McGrail et al. 2014).

The relationship between embryonic development pathways and tumor genetic programs has been widely investigated, yielding a multitude of hypotheses. For instance, an analogy between gastrulation and nuclear $\beta$-cat expression in the colonic adenoma-carcinoma process has been proposed, with the reactivation of embryonic programs in adult tissues being involved in the initiation of tumor development (Brabletz et al. 2005, Kirchner \& Brabletz 2000). Indeed, nuclear $\beta$-cat is a generic feature of initiation and progression in many tumors, and it is involved in three fundamental processes in embryonic development: stem cell formation, cell proliferation, and EMT (epithelial-mesenchymal transition) (Liu et al. 2015). Because the developmental $\beta$-cat pathway is mechanosensitive during embryonic morphogenetic movement (Brunet et al. 2013, Farge 2003, Kahn et al. 2009), $\beta$-cat target oncogene expression is proposed to be mechanically induced in healthy epithelial tissues in response to the mechanical pressure exerted by early-stage tumor growth nearby (Whitehead et al. 2008).

Experiments have revealed that the oncogenic $\beta$-cat pathway can be mechanically activated in response to artificial strain mimicking tumor growth pressure in colon explants, resulting in the mechanical induction of downstream c-Myc and Twist target gene expression (Whitehead et al. 2008) in $\mathrm{APC}^{1638 \mathrm{~N} /+}$ [Adenomatous Polyposis Coli protein heterozygous mutant (Fodde et al. 1994)] tissues. This ex vivo induction process is initiated by Src-family kinase-dependent mechanotransduction that triggers the phosphorylation of the Y654 site of $\beta$-cat, leading to the release of a pool of $\beta$-cat into the cytoplasm that cannot be fully degraded, owing to the defect in APC expression of $\mathrm{APC}^{1638 \mathrm{~N} /+}$ colon tissues.

Most of the experimental studies using direct mechanical tools in nature to study mechanotransduction in disease have been performed ex vivo in reconstituted systems, with manipulation of the stiffness of the cell culture substrate or extracellular matrix and of external pressure (Alexander et al. 2008, Jaalouk \& Lammerding 2009). Recently, an innovative method in mice allowing stable magnetization of deep tissues in vivo (connective colorectal tissues) on the timescale of weeks to months was developed using intravenous injection of ultramagnetic vesicles in the presence of a strong magnetic field gradient generated by a small intense magnet positioned subepidermally in front of the colon (Figure 6a) (Fernandez-Sanchez et al. 2015). After a couple of months of permanent physically induced direct mechanical strain application quantitatively mimicking tumor progression in vivo, activation of the tumorigenic $\beta$-cat pathway was observed, with c-Myc, axin-2, and zeb-1 overexpression and subsequent anomalous crypt formation (ACF) in the wild type and $\mathrm{APC}^{1638 \mathrm{~N} /+}$, and adenocarcinoma formation in the $\mathrm{APC}^{1638 \mathrm{~N} /+}$, in the initially healthy tissues (Figure $6 \boldsymbol{b}$ ). This was due to both the mechanically induced inhibition of the interaction of $\beta$-cat with E-cadherin in the junctions by the phosphorylation of the Y654 interaction site, mediating its cytoplasmic release, and the mechanically induced inhibition of GSK3 $\beta$ by the phosphorylation of Ser9, preventing cytoplasmic $\beta$-cat degradation and allowing its nuclear translocation and induction of downstream oncogene expression. Strikingly, the Src family Ret kinase was found to be mechanically activated (phosphorylated on Y1062) and to be upstream of both $\beta$-cat and GSK3 mechanically induced phosphorylation. Tumor growth pressure permanently applied on the weeks-to-few-months timescale thus pathologically overactivates the mechanosensitive tumorigenic $\beta$-cat pathway in healthy epithelial cells. The tumorigenic $\beta$-cat pathway was additionally found to be activated in the non-genetically altered healthy cells compressed by surrounding tumorous hyperproliferative cell domains, in line with a 

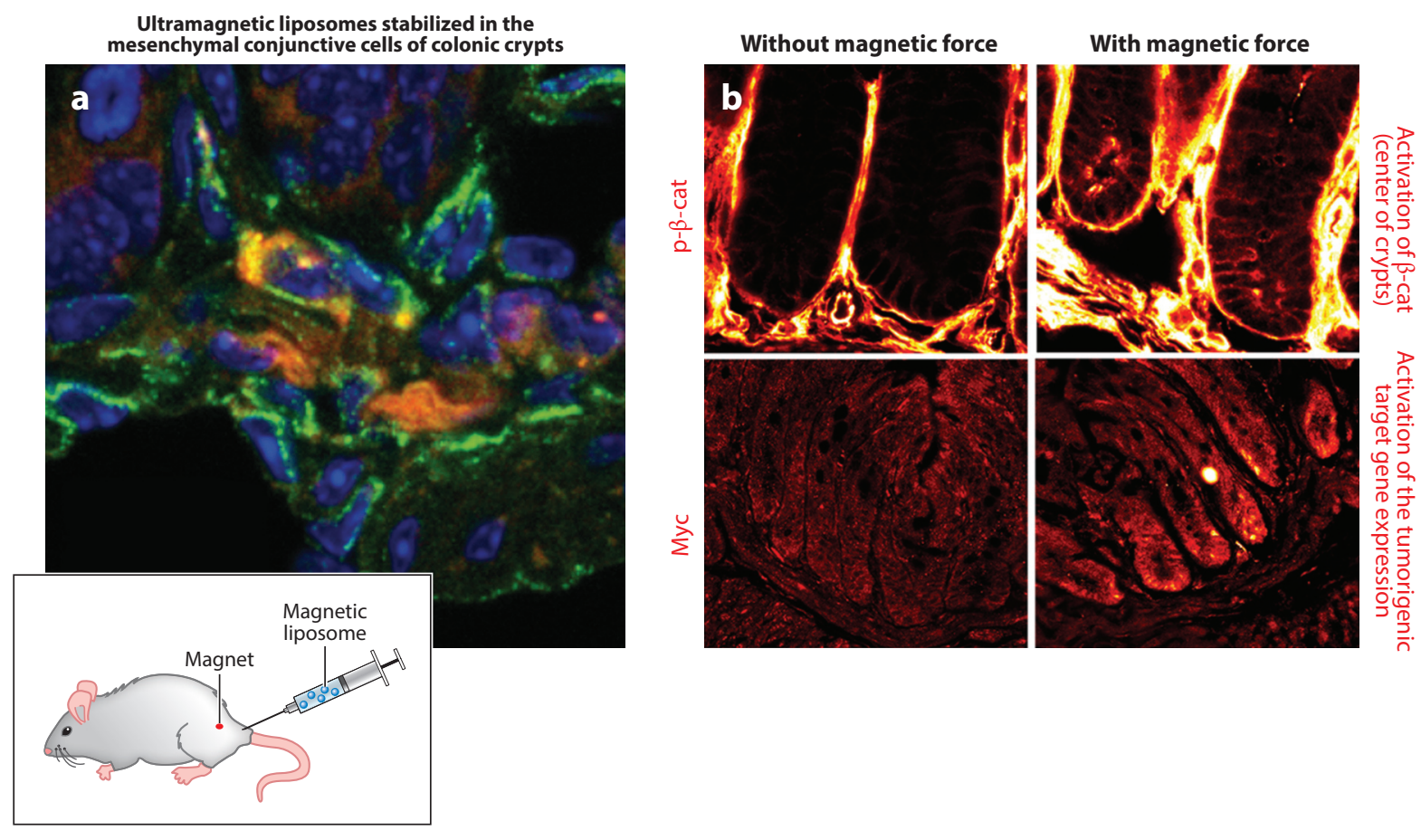

Figure 6

(a) Magnetic loading of mesenchymal cells conjunctive of epithelial crypt colonic cells (orange) submitted to a millimetric magnetic field gradient generates a permanent $1 \mathrm{kPa}$ pressure on the colon tissue, quantitatively mimicking tumor growth pressure on weeks to months, in vivo. (b) Resulting mechanical activation of the phosphorylation of the Y654 site of beta-catenin ( $\beta$-cat) (in the center of the crypts), leading to its release into the cytoplasm and nucleus (not shown), and to the expression of its tumorigenic target gene c-Myc.

mechanotransductive propagation of tumorigenesis from genetically altered hyperproliferative to healthy compressed epithelial cells (Fernandez-Sanchez et al. 2015).

Consistent with these findings, Samuel et al. (2011) have shown that actomyosin-mediated cellular tension increases tissue stiffness and $\beta$-cat activation in mouse adenocarcinomas, possibly inducing epidermal hyperplasia and tumor growth. Moreover, increased stiffness associated with fibrosis was found to reduce expression of the tumor repressor phosphatase and tensin homolog (PTEN) in breast tissue by modulating expression of the microRNA miR-18a in an integrin activation-dependent process involving $\beta$-cat and Myc (Mouw et al. 2014). Aberrant activation of the Wnt/ $\beta$-cat pathway is a major event in many types of cancers, including human hepatocellular carcinoma (Cavard et al. 2008, Colnot et al. 2004). Thus, pressure associated with tumor growth or fibrotic stiffness is potentially involved in a wide range of cancer types. The physics of growth instability up to a critical size, which accounts for many phase transition processes, coupled to mechanotransductive signals, has also been proposed to regulate tumor growth via hyperproliferation-induced tissue pressure (Basan et al. 2009, Delarue et al. 2014).

Several other mechanotransductive pathways are involved in tumor initiation, progression, and metastasis. NF- $\mathrm{BB}$, one of the first mechanosensitive transcription factors found in vitro (Resnick et al. 1993), is involved in hepatic inflammation, fibrosis, and cancer (Elsharkawy \& Mann 2007). NF- $\mathrm{kB}$ also has a role in bone and colon cancer (Linnewiel-Hermoni et al. 2014, Sebio et al. 2014). As discussed, YAP/TAZ also sense and mediate mechanical cues transduced by the cellular microenvironment (Dupont et al. 2011). In addition, they have been implicated in lung, 
bladder, and colorectal cancers (Hsu et al. 2015, Gao et al. 2014, Liang et al. 2014). The RhoROCK signaling pathway is associated with matrix stiffness-induced malignancy (Paszek et al. 2005, Samuel et al. 2011) and mechanotransduction (Jaalouk \& Lammerding 2009), and it has recently been implicated not only in ovarian but also in gastric cancer metastasis (McGrail et al. 2014, Matsuoka \& Yashiro 2014). A better understanding of the interplay between molecular and mechanical signals and its role in the initiation, progression, and metastasis of cancer will become indispensable for developing promising new therapies directed at cell contractility, the regulation of matrix rigidity, and pressure-induced tumorigenic, mechanosensitive signals. Such an understanding will benefit from in vitro and in vivo investigations, particularly within the context of development.

\section{CONCLUSION}

The highly deformable, soft-matter properties of proteins and mesoscopic cell structures such as membranes make many canonical biochemical pathways mechanosensitive. This has allowed cell functions to become sensitive to different types of environmental mechanical cues throughout evolution, from apical and basal sensing of the noncellular mechanical environment to junctional sensing of the mechanical state of the tissue itself in Metazoa. Active morphogenesis and differentiation of tissues are thus sensitive both to external mechanical cues inherent to the immediate physical environment of multicellular living systems and to internal mechanical cues inherent to the macroscopic shape and shape change of the living tissue system.

Mechanotransduction in development is based on the sensitivity of developmental pathways to the internal mechanical strains inherent to the developing, biomechanical morphology of the organism. It efficiently coordinates tissue shape changes with cell differentiation and allows feedback control of active morphogenesis. It also ensures coordination of collective cell behaviors thanks to the rapid and long-range propagation of mechanical strains across tissues. The involvement of mechanotransduction in responses to internal mechanical strains in development may have been inherited from favorable mechanotransductive responses in primitive multicellular systems to both internal transient shape changes and external mechanical cues, and mechanotransduction may have been critically involved in major evolutionary transitions, such as mesoderm emergence. Anomalous strains in adult tissues, for instance those associated with fibrosis or hyperproliferation, appear to overactivate the ancestral developmental pathways that coordinate morphogenesis and differentiation, thereby deregulating the differentiation/morphogenesis equilibrium that has led to the establishment of stable and viable organisms.

\section{DISCLOSURE STATEMENT}

The authors are not aware of any affiliations, memberships, funding, or financial holdings that might be perceived as affecting the objectivity of this review.

\section{AUTHOR CONTRIBUTIONS}

M.E.F. wrote the section on mechanotransduction in tumor progression, E.F., with T.B., wrote the section on the involvement of mechanotransduction in evolution, T.B. and J.C.R. created the sequence alignments, T.B. wrote the section on the phylogeny of mechanotransduction pathways and generated the corresponding genomic survey, J.C.R. wrote the section on mechanotransductive feedback in tissue growth regulation, and E.F. wrote other sections and coordinated the writing of the review. All authors made critical comments on the manuscript. 


\section{ACKNOWLEDGMENTS}

The Farge lab is funded by Labex CelTisPhyBio (grant 11-LBX-0038), Institut National du Cancer (INCa, grant PLBIO13-172), Fondation ARC pour la Recherche sur le Cancer (ARC, grants 5030 and 29324), the Agency of National Research (ANR, grants 09PIRI0013-01 and 11 BSV5014-01), and the Fondation pour la Recherche Médicale (FRM, grant Equipe labellisée FRM 2015 DEQ20150331702). J.C.R. is a Marie Curie fellow (PIEF-GA-2012-332422) and Labex CelTisPhyBio fellow.

\section{LITERATURE CITED}

Alexander NR, Branch KM, Parekh A, Clark ES, Lwueke LC, et al. 2008. Extracellular matrix rigidity promotes invadopodia activity. Curr. Biol. 18:1295-99

Aliee M, Roper JC, Landsberg KP, Pentzold C, Widmann TJ, et al. 2012. Physical mechanisms shaping the Drosophila dorsoventral compartment boundary. Curr. Biol. 22:967-76

Anderson PAV. 1989. Evolution of the First Nervous Systems. New York: Plenum

Aragona M, Panciera T, Manfrin A, Giulitti S, Michielin F, et al. 2013. A mechanical checkpoint controls multicellular growth through YAP/TAZ regulation by actin-processing factors. Cell 154:1047-59

Arendt D. 2004. Comparative aspects of gastrulation. In Gastrulation: From Cells to Embryo, ed. CD Stern, pp. 679-94. Cold Spring Harbor, NY: Cold Spring Harb. Lab. Press

Azzolin L, Panciera T, Soligo S, Enzo E, Bicciato S, et al. 2014. YAP/TAZ incorporation in the $\beta$-catenin destruction complex orchestrates the Wnt response. Cell 158:157-70

Bardet PL, Guirao B, Paoletti C, Serman F, Leopold V, et al. 2013. PTEN controls junction lengthening and stability during cell rearrangement in epithelial tissue. Dev. Cell 25:534-46

Basan M, Risler T, Joanny JF, Sastre-Garau X, Prost J. 2009. Homeostatic competition drives tumor growth and metastasis nucleation. HFSP 7. 3:265-72

Bechard M, Dalton S. 2009. Subcellular localization of glycogen synthase kinase 3beta controls embryonic stem cell self-renewal. Mol. Cell. Biol. 29(8):2092-104

Beloussov LV, Dorfman JG, Cherdantzev VG. 1975. Mechanical stresses and morphological patterns in amphibian embryos. 7. Embryol. Exp. Morphol. 34:559-74

Benham-Pyle BW, Pruitt BL, Nelson WJ. 2015. Cell adhesion. Mechanical strain induces E-cadherindependent Yap1 and beta-catenin activation to drive cell cycle entry. Science 348:1024-27

Bershadsky AD, Balaban NQ, Geiger B. 2003. Adhesion-dependent cell mechanosensitivity. Annu. Rev. Cell Dev. Biol. 19:677-95

Bertet C, Sulak L, Lecuit T. 2004. Myosin-dependent junction remodelling controls planar cell intercalation and axis elongation. Nature 429:667-71

Bissell MJ, Radisky D. 2001. Putting tumours in context. Nat. Rev. Cancer 1:46-54

Blankenship JT, Backovic ST, Sanny JS, Weitz O, Zallen JA. 2006. Multicellular rosette formation links planar cell polarity to tissue morphogenesis. Dev. Cell 11:459-70

Borghi N, Sorokina M, Shcherbakova OG, Weis WI, Pruitt BL, et al. 2012. E-cadherin is under constitutive actomyosin-generated tension that is increased at cell-cell contacts upon externally applied stretch. PNAS 109:12568-73

Bouclet A, Driquez B, Farge E. 2011. Mechanotransduction in mechanically coupled pulsating cells: transition to collective constriction and mesoderm invagination simulation. Phys. Biol. 8:066007

Bowdish KS, Yuan HE, Mitchell AP. 1994. Analysis of RIM11, a yeast protein kinase that phosphorylates the meiotic activator IME1. Mol. Cell. Biol. 14(12):7909-19

Bozic B, Derganc J, Svetina S. 2006. Blastula wall invagination examined on the basis of shape behavior of vesicular objects with laminar envelopes. Int. F. Dev. Biol. 50:143-50

Brabletz T, Jung A, Spaderna S, Hlubek F, Kirchner T. 2005. Opinion: Migrating cancer stem cells—an integrated concept of malignant tumour progression. Nat. Rev. Cancer 5:744-49

Brazill DT, Thorner J, Martin GS. 1997. Mck1, a member of the glycogen synthase kinase 3 family of protein kinases, is a negative regulator of pyruvate kinase in the yeast Saccharomyces cerevisiae. 7 . Bacteriol. 179(13):4415-18 
Brunet T, Bouclet A, Ahmadi P, Mitrossilis D, Driquez B, et al. 2013. Evolutionary conservation of early mesoderm specification by mechanotransduction in Bilateria. Nat. Commun. 4:2821

Buckley CD, Tan J, Anderson KL, Hanein D, Volkmann N, et al. 2014. Cell adhesion. The minimal cadherincatenin complex binds to actin filaments under force. Science 346(6209):1254211

Butcher DT, Alliston T, Weaver VM. 2009. A tense situation: forcing tumour progression. Nat. Rev. Cancer 9:108-22

Butler LC, Blanchard GB, Kabla AJ, Lawrence NJ, Welchman DP, et al. 2009. Cell shape changes indicate a role for extrinsic tensile forces in Drosophila germ-band extension. Nat. Cell Biol. 11:859-64

Cavard C, Colnot S, Audard V, Benhamouche S, Finzi L, et al. 2008. Wnt/ $\beta$-catenin pathway in hepatocellular carcinoma pathogenesis and liver physiology. Future Oncol. 4:647-60

Chalfie M. 2009. Neurosensory mechanotransduction. Nat. Rev. Mol. Cell Biol. 10:44-52

Chassot AA, Lossaint G, Turchi L, Meneguzzi G, Fisher D, et al. 2008. Confluence-induced cell cycle exit involves pre-mitotic CDK inhibition by p27(Kip1) and cyclin D1 downregulation. Cell Cycle 7:2038-46

Colnot S, Decaens T, Niwa-Kawakita M, Godard C, Hamard G, et al. 2004. Liver-targeted disruption of Apc in mice activates $\beta$-catenin signaling and leads to hepatocellular carcinomas. PNAS 101:17216-21

Connelly JT, Gautrot JE, Trappmann B, Tan DW-M, Donati G, et al. 2010. Actin and serum response factor transduce physical cues from the microenvironment to regulate epidermal stem cell fate decisions. Nat. Cell Biol. 12:711-18

Coste B, Mathur J, Schmidt M, Earley TJ, Ranade S, et al. 2010. Piezo1 and Piezo2 are essential components of distinct mechanically activated cation channels. Science 330:55-60

Coste B, Xiao B, Santos JS, Syeda R, Grandl J, et al. 2012. Piezo proteins are pore-forming subunits of mechanically activated channels. Nature 483:176-81

Daugherty RL, Gottardi CJ. 2007. Phospho-regulation of $\beta$-catenin adhesion and signaling functions. Physiology 22:303-9

Dawes-Hoang RE, Parmar KM, Christiansen AE, Phelps CB, Brand AH, Wieschaus EF. 2005. folded gastrulation, cell shape change and the control of myosin localization. Development 132:4165-78

Dayel MJ, Alegado RA, Fairclough SR, Levin TC, Nichols SA, et al. 2011. Cell differentiation and morphogenesis in the colony-forming choanoflagellate Salpingoeca rosetta. Dev. Biol. 357:73-82

Del Rio A, Perez-Jimenez R, Liu R, Roca-Cusachs P, Fernandez JM, Sheetz MP. 2009. Stretching single talin rod molecules activates vinculin binding. Science 323:638-41

Delarue M, Montel F, Vignjevic D, Prost J, Joanny JF, Cappello G. 2014. Compressive stress inhibits proliferation in tumor spheroids through a volume limitation. Biophys. F. 107:1821-8

Desprat N, Supatto W, Pouille P-A, Beaurepaire E, Farge E. 2008. Tissue deformation modulates Twist expression to determine anterior midgut differentiation in Drosophila embryos. Dev. Cell 15:470-77

Di-Poi N, Montoya-Burgos JI, Miller H, Pourquie O, Milinkovitch MC, Duboule D. 2010. Changes in Hox genes' structure and function during the evolution of the squamate body plan. Nature 464:99-103

Dong J, Feldmann G, Huang J, Wu S, Zhang N, et al. 2007. Elucidation of a universal size-control mechanism in Drosophila and mammals. Cell 130:1120-33

Dufort CC, Paszek MJ, Weaver VM. 2011. Balancing forces: architectural control of mechanotransduction. Nat. Rev. Mol. Cell Biol. 12:308-19

Dupont S, Morsut L, Aragona M, Enzo E, Giulitti S, et al. 2011. Role of YAP/TAZ in mechanotransduction. Nature 474:179-83

Edwards CM, Chapman SJ. 2007. Biomechanical modelling of colorectal crypt budding and fission. Bull. Math. Biol. 69:1927-42

Elsharkawy AM, Mann DA. 2007. Nuclear factor- $\kappa B$ and the hepatic inflammation-fibrosis-cancer axis. Hepatology 46:590-7

Engler AJ, Sen S, Sweeney HL, Discher DE. 2006. Matrix elasticity directs stem cell lineage specification. Cell 126:677-89

Farge E. 2003. Mechanical induction of Twist in the Drosophila foregut/stomodeal primordium. Curr. Biol. 13:1365-77

Fernandez-Gonzalez R, de Matos Simoes S, Roper JC, Eaton S, Zallen JA. 2009. Myosin II dynamics are regulated by tension in intercalating cells. Dev. Cell 17:736-43 
Fernandez-Sanchez ME, Barbier S, Whitehead J, Bealle G, Michel A, et al. 2015. Mechanical induction of the tumorigenic beta-catenin pathway by tumour growth pressure. Nature 523:92-95

Filas BA, Bayly PV, Taber LA. 2011. Mechanical stress as a regulator of cytoskeletal contractility and nuclear shape in embryonic epithelia. Ann. Biomed. Eng. 39:443-54

Fodde R, Edelmann W, Yang K, Vanleeuwen C, Carlson C, et al. 1994. A targeted chain-termination mutation in the mouse Apc gene results in multiple intestinal tumors. PNAS 91:8969-73

Foe VE. 1989. Mitotic domains reveal early commitment of cells in Drosophila embryos. Development 107:1-22

Gao Y, Shi Q, Xu S, Du C, Liang L, et al. 2014. Curcumin promotes KLF5 proteasome degradation through downregulating YAP/TAZ in bladder cancer cells. Int. 7. Mol. Sci. 15:15173-87

García Fernández BG, Gaspar P, Brás-Pereira C, Jezowska B, Rebelo SR, Janody F. 2011. Actin-capping protein and the Hippo pathway regulate F-actin and tissue growth in Drosophila. Development 138:233746

Geiger B, Spatz JP, Bershadsky AD. 2009. Environmental sensing through focal adhesions. Nat. Rev. Mol. Cell Biol. 10:21-33

Ghajar CM, Bissell MJ. 2008. Extracellular matrix control of mammary gland morphogenesis and tumorigenesis: insights from imaging. Histochem. Cell Biol. 130:1105-18

Gospodarowicz D, Greenburg G, Birdwell CR. 1978. Determination of cellular shape by the extracellular matrix and its correlation with the control of cellular growth. Cancer Res. 38:4155-71

Grashoff C, Hoffman BD, Brenner MD, Zhou R, Parsons M, et al. 2010. Measuring mechanical tension across vinculin reveals regulation of focal adhesion dynamics. Nature 466:263-66

Guo TB, Chan KC, Hakovirta H, Xiao Y, Toppari J, et al. 2003. Evidence for a role of glycogen synthase kinase-3 beta in rodent spermatogenesis. f. Androl. 24(3):332-42

Haeckel E. 1874. Die Gastraea-Theorie, die phylogenetische Klassifikation des Tierreichs, und die Homologie der Keimblätter. Z. Naturwiss. Fena 8:1-55

Hamant O, Heisler MG, Jonsson H, Krupinski P, Uyttewaal M, et al. 2008. Developmental patterning by mechanical signals in Arabidopsis. Science 322:1650-55

Hanahan D, Weinberg RA. 2011. Hallmarks of cancer: the next generation. Cell 144:646-74

Hannezo E, Prost J, Joanny JF. 2011. Instabilities of monolayered epithelia: shape and structure of villi and crypts. Phys. Rev. Lett. 107:078104

Harvey KF, Zhang X, Thomas DM. 2013. The Hippo pathway and human cancer. Nat. Rev. Cancer 13:246-57

He B, Doubrovinski K, Polyakov O, Wieschaus E. 2014. Apical constriction drives tissue-scale hydrodynamic flow to mediate cell elongation. Nature 508:392-96

Hens JR, Wilson KM, Dann P, Chen X, Horowitz MC, Wysolmerski JJ. 2005. TOPGAL mice show that the canonical Wnt signaling pathway is active during bone development and growth and is activated by mechanical loading in vitro. F. Bone Miner. Res. 20:1103-13

Hiramatsu R, Matsuoka T, Kimura-Yoshida C, Han SW, Mochida K, et al. 2013. External mechanical cues trigger the establishment of the anterior-posterior axis in early mouse embryos. Dev. Cell 27:131-44

Hirata Y, Andoh T, Asahara T, Kikuchi A. 2003. Yeast glycogen synthase kinase-3 activates Msn2p-dependent transcription of stress responsive genes. Mol. Biol. Cell 14(1):302-12

Hove JR, Koster RW, Forouhar AS, Acevedo-Bolton G, Fraser SE, Gharib M. 2003. Intracardiac fluid forces are an essential epigenetic factor for embryonic cardiogenesis. Nature 421:172-77

Hsu YL, Hung JY, Chou SH, Huang MS, Tsai MJ, et al. 2015. Angiomotin decreases lung cancer progression by sequestering oncogenic YAP/TAZ and decreasing Cyr61 expression. Oncogene 34:4056-68

Huang S, Ingber DE. 2000. Shape-dependent control of cell growth, differentiation, and apoptosis: switching between attractors in cell regulatory networks. Exp. Cell Res. 261:91-103

Hufnagel L, Teleman AA, Rouault H, Cohen SM, Shraiman BI. 2007. On the mechanism of wing size determination in fly development. PNAS 104:3835-40

Huh D, Matthews BD, Mammoto A, Montoya-Zavala M, Hsin HY, Ingber DE. 2010. Reconstituting organlevel lung functions on a chip. Science 328:1662-68

Idema T, Dubuis JO, Kang L, Manning ML, Nelson PC, et al. 2013. The syncytial Drosophila embryo as a mechanically excitable medium. PLOS ONE 8:e77216 
Jaalouk DE, Lammerding J. 2009. Mechanotransduction gone awry. Nat. Rev. Mol. Cell. Biol. 10:63-73

Jaegerstem G. 1956. The early phylogeny of the metazoa. The bilaterogastrea theory. Zool. Bidrag. 30:321-54 Jin AJ, Nossal R. 2000. Rigidity of triskelion arms and clathrin nets. Biophys. F. 78:1183-94

Kahn J, Shwartz Y, Blitz E, Krief S, Sharir A, et al. 2009. Muscle contraction is necessary to maintain joint progenitor cell fate. Dev. Cell 16:734-43

Kalamegham R, Sturgill D, Siegfried E, Oliver B. 2007. Drosophila mojoless, a retroposed GSK-3, has functionally diverged to acquire an essential role in male fertility. Mol. Biol. Evol. 24(3):732-42

Kassir Y, Rubin-Bejerano I, Mandel-Gutfreund Y. 2006. The Saccharomyces cerevisiae GSK-3 beta homologs. Curr. Drug Targets 7(11):1455-65

Keller R, Davidson L, Edlund A, Elul T, Ezin M, et al. 2000. Mechanisms of convergence and extension by cell intercalation. Philos. Trans. R. Soc. B 355:897-922

Kim K, Ossipova O, Sokol SY. 2014. Neural crest specification by inhibition of the ROCK/Myosin II pathway. Stem Cells 33(3):674-85

King N, Westbrook MJ, Young SL, Kuo A, Abedin M, et al. 2008. The genome of the choanoflagellate Monosiga brevicollis and the origin of metazoans. Nature 451:783-88

Kirchner T, Brabletz T. 2000. Patterning and nuclear $\beta$-catenin expression in the colonic adenoma-carcinoma sequence. Analogies with embryonic gastrulation. Am. 7. Pathol. 157:1113-21

Kris AS, Kamm RD, Sieminski AL. 2008. VASP involvement in force-mediated adherens junction strengthening. Biochem. Biophys. Res. Commun. 375:134-38

Landsberg KP, Farhadifar R, Ranft J, Umetsu D, Widmann TJ, et al. 2009. Increased cell bond tension governs cell sorting at the Drosophila anteroposterior compartment boundary. Curr. Biol. 19:1950-55

Leckband DE, Le Duc Q, Wang N, de Rooij J. 2011. Mechanotransduction at cadherin-mediated adhesions. Curr. Opin. Cell Biol. 23:523-30

Legoff L, Rouault H, Lecuit T. 2013. A global pattern of mechanical stress polarizes cell divisions and cell shape in the growing Drosophila wing disc. Development 140:4051-59

Li J, Hou B, Tumova S, Muraki K, Bruns A, et al. 2014. Piezo1 integration of vascular architecture with physiological force. Nature 515:279-82

Liang K, Zhou G, Zhang Q, Li J, Zhang C. 2014. Expression of Hippo pathway in colorectal cancer. Saudi f. Gastroenterol. 20:188-94

Linnewiel-Hermoni K, Motro Y, Miller Y, Levy J, Sharoni Y. 2014. Carotenoid derivatives inhibit nuclear factor $\mathrm{kB}$ activity in bone and cancer cells by targeting key thiol groups. Free Radic. Biol. Med. 75:105-20

Liu H, Yin J, Wang H, Jiang G, Deng M, et al. 2015. FOXO3a modulates WNT/ $\beta$-catenin signaling and suppresses epithelial-to-mesenchymal transition in prostate cancer cells. Cell Signal. 27(3):510-18

Liu Z, Tan JL, Cohen DM, Yang MT, Sniadecki NJ, et al. 2010. Mechanical tugging force regulates the size of cell-cell junctions. PNAS 107:9944-49

Mammoto T, Mammoto A, Torisawa YS, Tat T, Gibbs A, et al. 2011. Mechanochemical control of mesenchymal condensation and embryonic tooth organ formation. Dev. Cell 21:758-69

Manning AJ, Peters KA, Peifer M, Rogers SL. 2013. Regulation of epithelial morphogenesis by the G proteincoupled receptor Mist and its ligand Fog. Sci. Signal. 6:ra98

Mao Y, Ge X, Frank CL, Madison JM, Koehler AN, et al. 2009. Disrupted in Schizophrenia 1 regulates neuronal progenitor proliferation via modulation of GSK3 $\beta / \beta$-catenin signaling. Cell 136(6):1017-31

Mao Y, Tournier AL, Hoppe A, Kester L, Thompson BJ, Tapon N. 2013. Differential proliferation rates generate patterns of mechanical tension that orient tissue growth. EMBO F. 32:2790-803

Martin AC, Kaschube M, Wieschaus EF. 2009. Pulsed contractions of an actin-myosin network drive apical constriction. Nature 457:495-99

Martin AC. 2009. Pulsation and stabilization: contractile forces that underlie morphogenesis. Dev. Biol. 341:114-25

Mason FM, Tworoger M, Martin AC. 2013. Apical domain polarization localizes actin-myosin activity to drive ratchet-like apical constriction. Nat. Cell Biol. 15:926-36

Matsuoka T, Yashiro M. 2014. Rho/ROCK signaling in motility and metastasis of gastric cancer. World F. Gastroenterol. 20:13756-66

McBeath R, Pirone DM, Nelson CM, Bhadriraju K, Chen CS. 2004. Cell shape, cytoskeletal tension, and RhoA regulate stem cell lineage commitment. Dev. Cell 6:483-95 
McGrail DJ, Kieu QMN, Dawson MR. 2014. The malignancy of metastatic ovarian cancer cells is increased on soft matrices through a mechanosensitive Rho-ROCK pathway. 7. Cell Sci. 127:2621-26

Monier B, Gettings M, Gay G, Mangeat T, Schott S, et al. 2015. Apico-basal forces exerted by apoptotic cells drive epithelium folding. Nature 518:245-48

Monier B, Pelissier-Monier A, Brand AH, Sanson B. 2010. An actomyosin-based barrier inhibits cell mixing at compartmental boundaries in Drosophila embryos. Nat. Cell Biol. 12:60-65

Morize P, Christiansen AE, Costa M, Parks S, Wieschaus E. 1998. Hyperactivation of the folded gastrulation pathway induces specific cell shape changes. Development 125:589-97

Mouw JK, Yui Y, Damiano L, Bainer RO, Lakins JN, et al. 2014. Tissue mechanics modulate microRNAdependent PTEN expression to regulate malignant progression. Nat. Med. 20:360-67

Nassoy P, Lamaze C. 2012. Stressing caveolae new role in cell mechanics. Trends Cell Biol. 22:381-89

Neigeborn L, Mitchell AP. 1991. The yeast MCK1 gene encodes a protein kinase homolog that activates early meiotic gene expression. Genes Dev. 5(4):533-48

Nichols SA, Roberts BW, Richter DJ, Fairclough SR, King N. 2012. Origin of metazoan cadherin diversity and the antiquity of the classical cadherin/ $\beta$-catenin complex. Proc. Natl. Acad. Sci. USA 109:13046-51

Nielsen C. 2012. Animal Evolution: Interrelationships of the Living Phyla. Oxford, UK: Oxford Univ. Press

Nienhaus U, Aegerter-Wilmsen T, Aegerter CM. 2009. Determination of mechanical stress distribution in Drosophila wing discs using photoelasticity. Mech. Dev. 126:942-49

Nusse R. 2015. Wnt target genes. The Wnt Homepage, updated May 2015. http://web.stanford.edu/group/ nusselab/cgi-bin/wnt/target_genes

Odell GM, Oster G, Alberch P, Burnside B. 1981. The mechanical basis of morphogenesis. I. Epithelial folding and invagination. Dev. Biol. 85:446-62

Oh H, Irvine KD. 2008. In vivo regulation of Yorkie phosphorylation and localization. Development 135:108188

Ohteki T, Parsons M, Zakarian A, Jones RG, Nguyen LT, et al. 2000. Negative regulation of T cell proliferation and interleukin 2 production by the serine threonine kinase Gsk-3. F. Exp. Med. 192(1):99-104

Papusheva E, Heisenberg C-P. 2010. Spatial organization of adhesion: force-dependent regulation and function in tissue morphogenesis. EMBO 7. 29:2753-68

Pare AC, Vichas A, Fincher CT, Mirman Z, Farrell DL, et al. 2014. A positional Toll receptor code directs convergent extension in Drosophila. Nature 515:523-27

Paszek MJ, Zahir N, Johnson KR, Lakins JN, Rozenberg GI, et al. 2005. Tensional homeostasis and the malignant phenotype. Cancer Cell 8:241-54

Pickup MW, Mouw JK, Weaver VM. 2014. The extracellular matrix modulates the hallmarks of cancer. EMBO Rep. 15:1243-53

Pirone DM, Liu WF, Ruiz SA, Gao L, Raghavan S, et al. 2006. An inhibitory role for FAK in regulating proliferation: a link between limited adhesion and RhoA-ROCK signaling. F. Cell Biol. 174:277-88

Pouille PA, Ahmadi P, Brunet AC, Farge E. 2009. Mechanical signals trigger myosin II redistribution and mesoderm invagination in Drosophila embryos. Sci. Signal 2:ra16

Pouille PA, Farge E. 2008. Hydrodynamic simulation of multicellular embryo invagination. Phys. Biol. 5:15005

Ranade SS, Woo S-H, Dubin AE, Moshourab RA, Wetzel C, et al. 2014. Piezo2 is the major transducer of mechanical forces for touch sensation in mice. Nature 516:121-25

Rauch C, Brunet AC, Deleule J, Farge E. 2002. C2C12 myoblast/osteoblast transdifferentiation steps enhanced by epigenetic inhibition of BMP2 endocytosis. Am. F. Physiol. Cell Physiol. 283:C235-43

Rauch C, Farge E. 2000. Endocytosis switch controlled by transmembrane osmotic pressure and phospholipid number asymmetry. Biophys. f. 78:3036-47

Raucher D, Sheetz MP. 1999. Membrane expansion increases endocytosis rate during mitosis. 7. Cell Biol. 144:497-506

Rentzsch F, Hobmayer B, Holstein TW. 2005. Glycogen synthase kinase 3 has a proapoptotic function in Hydra gametogenesis. Dev. Biol. 278(1):1-12

Resnick N, Collins T, Atkinson W, Bonthron DT, Dewey CF Jr, Gimbrone MA Jr. 1993. Platelet-derived growth factor $\mathrm{B}$ chain promoter contains a cis-acting fluid shear-stress-responsive element. PNAS 90:4591-95 
Riveline D, Zamir E, Balaban NQ, Schwarz US, Ishizaki T, et al. 2001. Focal contacts as mechanosensors: externally applied local mechanical force induces growth of focal contacts by an mDia1-dependent and ROCK-independent mechanism. F. Cell Biol. 153:1175-86

Roura S, Miravet S, Piedra J, Garcia de Herreros A, Dunach M. 1999. Regulation of E-cadherin/Catenin association by tyrosine phosphorylation. 7. Biol. Chem. 274:36734-40

Rubashkin MG, Cassereau L, Bainer R, Dufort CC, Yui Y, et al. 2014. Force engages vinculin and promotes tumor progression by enhancing PI3K activation of phosphatidylinositol (3,4,5)-triphosphate. Cancer Res. 74:4597-611

Saidi Y, Hearn TJ, Coates JC. 2012. Function and evolution of "green" GSK3/Shaggy-like kinases. Trends Plant Sci. 17(1):39-46

Samuel MS, Lopez JI, McGhee EJ, Croft DR, Strachan D, et al. 2011. Actomyosin-mediated cellular tension drives increased tissue stiffness and $\beta$-catenin activation to induce epidermal hyperplasia and tumor growth. Cancer Cell 19:776-91

Sansores-Garcia L, Bossuyt W, Wada K-I, Yonemura S, Tao C, et al. 2011. Modulating F-actin organization induces organ growth by affecting the Hippo pathway. EMBO 7. 30:2325-35

Sawada Y, Tamada M, Dubin-Thaler BJ, Cherniavskaya O, Sakai R, et al. 2006. Force sensing by mechanical extension of the Src family kinase substrate p130Cas. Cell 127:1015-26

Schilde C, Araki T, Williams H, Harwood A, Williams JG. 2004. GSK3 is a multifunctional regulator of Dictyostelium development. Development 131(18):4555-65

Sebé-Pedrós A, Irimia M, Campo JD, Parra-Acero H, Russ C, et al. 2013. Regulated aggregative multicellularity in a close unicellular relative of metazoa. eLife 2:e01287

Sebé-Pedrós A, Roger AJ, Lang FB, King N, Ruiz-Trillo I. 2010. Ancient origin of the integrin-mediated adhesion and signaling machinery. PNAS 107:10142-47

Sebio A, Gerger A, Matsusaka S, Yang D, Zhang W, et al. 2014. Genetic variants within obesity-related genes are associated with tumor recurrence in patients with stages II/III colon cancer. Pharmacogenet. Genomics 25:30-37

Seher TC, Narasimha M, Vogelsang E, Leptin M. 2007. Analysis and reconstitution of the genetic cascade controlling early mesoderm morphogenesis in the Drosophila embryo. Mech. Dev. 124:167-79

Shivashankar GV. 2011. Mechanosignaling to the cell nucleus and gene regulation. Annu. Rev. Biophys. 40:36178

Shraiman BI. 2005. Mechanical feedback as a possible regulator of tissue growth. PNAS 102:3318-23

Spudich JA. 2006. Molecular motors take tension in stride. Cell 126:242-4

St. Johnston D, Nusslein-Volhard C. 1992. The origin of pattern and polarity in the Drosophila embryo. Cell 68:201-19

Suga H, Chen Z, de Mendoza A, Sebé-Pedrós A, Brown MW, et al. 2013. The Capsaspora genome reveals a complex unicellular prehistory of animals. Nat. Commun. 4:2325

Swift J, Ivanovska IL, Buxboim A, Harada T, Dingal PC, et al. 2013. Nuclear lamin-A scales with tissue stiffness and enhances matrix-directed differentiation. Science 341:1240104

Tan Y, Tajik A, Chen J, Jia Q, Chowdhury F, et al. 2014. Matrix softness regulates plasticity of tumourrepopulating cells via H3K9 demethylation and Sox2 expression. Nat. Commun. 5:4619

Thompson DAW. 1917. On Growth and Form. Cambridge, UK: Cambridge Univ. Press

Tokoyama Y, Peralta XG, Wells AR, Kierart DP, Edwards GS. 2008. Apoptotic force and tissue dynamics during Drosophila embryogenesis. Science 321:1683-86

Tseng A-S, Engel FB, Keating MT. 2006. The GSK-3 inhibitor BIO promotes proliferation in mammalian cardiomyocytes. Chem. Biol. 13(9):957-63

Ukena TE, Goldman E, Benjamin TL, Karnovsky MJ. 1976. Lack of correlation between agglutinability, the surface distribution of con A and post-confluence inhibition of cell division in ten cell lines. Cell 7:213-22

Uyttewaal M, Burian A, Alim K, Landrein B, Borowska-Wykret D, et al. 2012. Mechanical stress acts via katanin to amplify differences in growth rate between adjacent cells in Arabidopsis. Cell 149:439-51

Veelen WV, Le NH, Helvensteijn W, Blonden L, Theeuwes M, et al. 2011. $\beta$-Catenin tyrosine 654 phosphorylation increases Wnt signalling and intestinal tumorigenesis. Gut 60:1204-12

Vermot J, Forouhar AS, Liebling M, Wu D, Plummer D, et al. 2009. Reversing blood flows act through klf2a to ensure normal valvulogenesis in the developing heart. PLOS Biol. 7:e1000246 
Wada KI, Itoga K, Okano T, Yonemura S, Sasaki H. 2011. Hippo pathway regulation by cell morphology and stress fibers. Development 138:3907-14

Wang N, Tytell JD, Ingber DE. 2009. Mechanotransduction at a distance: mechanically coupling the extracellular matrix with the nucleus. Nat. Rev. Mol. Cell Biol. 10:75-82

Wang Y, Riechmann V. 2007. The role of the actomyosin cytoskeleton in coordination of tissue growth during Drosophila oogenesis. Curr. Biol. 17:1349-55

Wartlick O, Mumcu P, Julicher F, Gonzalez-Gaitan M. 2011. Understanding morphogenetic growth control-lessons from flies. Nat. Rev. Mol. Cell Biol. 12:594-604

Whitehead J, Vignjevic D, Fuetterer C, Beaurepaire E, Robine S, Farge E. 2008. Mechanical factors activate $\beta$-catenin-dependent oncogene expression in $\mathrm{APC}^{1638 \mathrm{~N} /+}$ mouse colon. HFSP 7. 2:286-94

Williams F, Tew HA, Paul CE, Adams JC. 2014. The predicted secretomes of Monosiga brevicollis and Capsaspora owczarzaki, close unicellular relatives of metazoans, reveal new insights into the evolution of the metazoan extracellular matrix. Matrix Biol. 37:60-68

Wolpert L. 1992. Gastrulation and the evolution of development. Development 1992(Suppl.):7-13

Wozniak MA, Chen CS. 2009. Mechanotransduction in development: a growing role for contractility. Nat. Rev. Mol. Cell Biol. 10:34-43

Xie S, Martin AC. 2015. Intracellular signalling and intercellular coupling coordinate heterogeneous contractile events to facilitate tissue folding. Nat. Commun. 6:7161

Yonemura S. 2011. A mechanism of mechanotransduction at the cell-cell interface: emergence of $\alpha$-catenin as the center of a force-balancing mechanism for morphogenesis in multicellular organisms. BioEssays $33: 732-36$

Yonemura S, Wada Y, Watanabe T, Nagafuchi A, Shibata M. 2010. $\alpha$-Catenin as a tension transducer that induces adherens junction development. Nat. Cell Biol. 12:533-42

Young PE, Pesacreta TC, Kiehart DP. 1991. Dynamic changes in the distribution of cytoplasmic myosin during Drosophila embryogenesis. Development 111:1-14

Yu H, Mouw JK, Weaver VM. 2011. Forcing form and function: biomechanical regulation of tumor evolution. Trends Cell Biol. 21:47-56

Zhang H, Landmann F, Zahreddine H, Rodriguez D, Koch M, Labouesse M. 2011. A tension-induced mechanotransduction pathway promotes epithelial morphogenesis. Nature 471:99-103

Zhao B, Li L, Wang L, Wang CY, Yu J, Guan KL. 2012. Cell detachment activates the Hippo pathway via cytoskeleton reorganization to induce anoikis. Genes Dev. 26:54-68

Zhao B, Wei X, Li W, Udan RS, Yang Q, et al. 2007. Inactivation of YAP oncoprotein by the Hippo pathway is involved in cell contact inhibition and tissue growth control. Genes Dev. 21:2747-61

Zhu X, Assoian RK. 1995. Integrin-dependent activation of MAP kinase: a link to shape-dependent cell proliferation. Mol. Biol. Cell. 6:273-82 


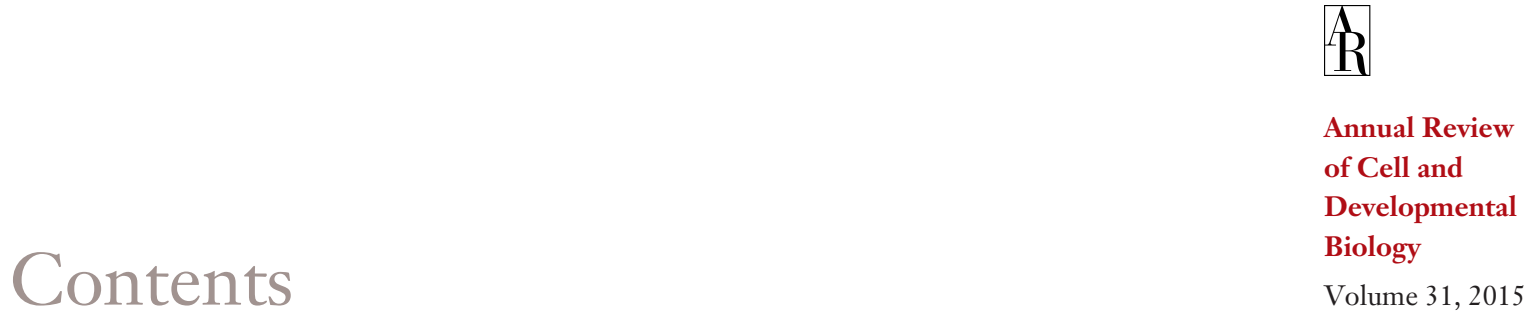

Perspective

Lewis Wolpert ..................................................... 1

Sizing up to Divide: Mitotic Cell-Size Control in Fission Yeast Elizabeth Wood and Paul Nurse ..................................................... 11

Translating the Genome in Time and Space: Specialized Ribosomes, RNA Regulons, and RNA-Binding Proteins Zhen Shi and Maria Barna ................................................. 31

Motors, Anchors, and Connectors: Orchestrators of Organelle Inheritance Barbara Knoblach and Richard A. Rachubinski...

Mechanism and Regulation of Cytoplasmic Dynein Michael A. Cianfrocco, Morgan E. DeSantis, Andres E. Leschziner, and Samara L. Reck-Peterson

The Pathway of Collagen Secretion Vivek Malhotra and Patrik Erlmann

The Hepatitis B Virus Receptor Wenhui Li 125

Prions: What Are They Good For?

Kausik Si

Bacterial Chromosome Organization and Segregation

Anjana Badrinarayanan, Tung B.K. Le, and Michael T. Laub

Modulation of Host Cell Biology by Plant Pathogenic Microbes Ruth Le Fevre, Edouard Evangelisti, Thomas Rey, and Sebastian Schornack

Ion Channels in Development and Cancer Emily Bates

Musashi Signaling in Stem Cells and Cancer

Raymond G. Fox, Frederick D. Park, Claire S. Koechlein, Marcie Kritzik, and Tannishtha Reya 
Mini-Gut Organoids: Reconstitution of Stem Cell Niche

Shoichi Date and Toshiro Sato

Genetics of Gonadal Stem Cell Renewal

Leab Joy Greenspan, Margaret de Cuevas, and Erika Matunis ....

Studying Lineage Decision-Making In Vitro: Emerging Concepts and Novel Tools

Stefan Semrau and Alexander van Oudenaarden

Feeling Force: Physical and Physiological Principles Enabling Sensory

Mechanotransduction

Samata Katta, Michael Krieg, and Miriam B. Goodman

Mechanotransduction's Impact on Animal Development, Evolution, and Tumorigenesis

Maria-Elena Fernandez-Sanchez, Thibaut Brunet, Jens-Christian Röper, and Emmanuel Farge

Comparative Analysis of Gene Regulatory Networks: From Network

Reconstruction to Evolution

Dawn Thompson, Aviv Regev, and Sushmita Roy....

The Developmental Control of Transposable Elements

and the Evolution of Higher Species

Marc Friedli and Didier Trono

Toward a Synthesis of Developmental Biology with Evolutionary

Theory and Ecology

Ralf7. Sommer and Melanie G. Mayer

Metabolism and Epigenetics

Ryan Janke, Anne E. Dodson, and Fasper Rine....

Stress Signaling Between Organs in Metazoa

Edward Owusu-Ansah and Norbert Perrimon

Placenta: The Forgotten Organ

Emin Maltepe and Susan 7. Fisher

Lung Endoderm Morphogenesis: Gasping for Form and Function

Daniel T. Swarr and Edward E. Morrisey

Polarized Protein Transport and Lumen Formation During Epithelial

Tissue Morphogenesis

Alex 7. Blasky, Anthony Mangan, and Rytis Prekeris ...

Structure, Regulation, and Functional Diversity of Microvilli on the Apical Domain of Epithelial Cells

Cécile Sauvanet, Jessica Wayt, Thaher Pelaseyed, and Anthony Bretscher.... 
Wnt-Frizzled/Planar Cell Polarity Signaling: Cellular Orientation by Facing the Wind (Wnt)

Yingzi Yang and Marek Mlodzik 623

The Ins and Outs of Polarized Axonal Domains

Daniel R. Zollinger, Kelli L. Baalman, and Mattbew N. Rasband

Assembly and Function of Spinal Circuits for Motor Control

Catarina Catela, Maggie M. Shin, and feremy S. Dasen

Generating Neuronal Diversity in the Mammalian Cerebral Cortex

Simona Lodato and Paola Arlotta

Monoallelic Expression of Olfactory Receptors

Kevin Monahan and Stavros Lomvardas

Development of Dendritic Form and Function

Fulie L. Lefebvre, Joshua R. Sanes, and Feremy N. Kay

Sculpting Neural Circuits by Axon and Dendrite Pruning

Martin M. Riccomagno and Alex L. Kolodkin 779

\section{Indexes}

Cumulative Index of Contributing Authors, Volumes 27-31

Cumulative Index of Chapter Titles, Volumes 27-31

\section{Errata}

An online log of corrections to Annual Review of Cell and Developmental Biology articles may be found at http://www.annualreviews.org/errata/cellbio 